\title{
In-depth analysis of raw bio-oil and its hydrodeoxygenated products for a comprehensive catalyst performance evaluation
}

Idoia Hita, ${ }^{a, b^{*}}$ Tomás Cordero-Lanzac, ${ }^{a, c}$ Timo Kekäläinen, ${ }^{d}$ Ogechukwu Okafor, ${ }^{d}$ José Rodríguez-Mirasol, ${ }^{c}$ Tomás Cordero,${ }^{c}$ Javier Bilbao, ${ }^{a}$ Janne Jänis,${ }^{d}$ Pedro Castano,${ }^{a, b}$

${ }^{a}$ Department of Chemical Engineering, University of the Basque Country (UPV/EHU), PO Box 644-48080, Bilbao, Spain

${ }^{b}$ Multiscale Reaction Engineering, KAUST Catalysis Center (KCC), King Abdullah University of Science and Technology (KAUST), Thuwal, 23955-6900, Saudi Arabia

${ }^{c}$ Department of Chemical Engineering, Universidad de Málaga, Andalucia Tech., Campus de Teatinos s/n, 29010, Málaga, Spain

${ }^{d}$ Department of Chemistry, University of Eastern Finland, PO Box 111, FI-80101, Joensuu, Finland

* Corresponding author: idoia.hitadelolmo@kaust.edu.sa 


\begin{abstract}
Biomass pyrolysis liquids (bio-oils) unavoidably require catalytic hydrodeoxygenation (HDO) for their upgrading and stabilization for commercial usage. The complex composition of bio-oil constrains the fundamental kinetic understanding of the HDO. Here, we propose a multi-technique methodology to compositionally assess the complete spectrum of the HDO reactants and products, and then use it to pre-evaluate different catalysts in the HDO of a raw bio-oil obtained from black poplar. The used techniques are: micro chromatography (GC), GC with mass spectrometry (MS), bidimensional $\mathrm{GC} \times \mathrm{GC} / \mathrm{MS}$, elemental analysis, gel permeation chromatography, Karl-Fischer, thermogravimetric analysis, as well as Fourier ion cyclotron resonance mass spectrometry (FTICR/MS) using different ionization sources (ESI and APPI). The latter technique allows for the assessment of the heaviest and most refractory oxygenates in bio-oil, which have a pivotal role in the HDO catalyst performance. Three activated carbon-supported catalysts based on PtPd, NiW and CoMo mixed with a commercial HZSM-5 zeolite were used. We have been able to evaluate the multiple facets of catalyst performance: production of gases, catalytic coke, thermal lignin and most importantly, the aqueous and organic product fractions (hydrodeoxygenation of heavy species and production of light aromatics). The results of the detailed analysis methodology highlight their potential for the understanding of the HDO mechanism and for a detailed catalyst screening.
\end{abstract}

Keywords: raw bio-oil, hydrodeoxygenation, oxygenates, aromatics, ultrahigh-resolution spectroscopy 


\section{Introduction}

The necessity to achieve a less fossil energy-dependent energetic scenario is driving increasing interest towards biomass as an alternative energy source. ${ }^{1,2}$ At an industrial scale, the main routes for biomass conversion are fermentation, gasification and fast pyrolysis. ${ }^{3,4}$ Among these, fast pyrolysis is the most appealing, given its limited environmental impact, the readiness of different pyrolysis technologies, and also the possibilities it offers for the subsequent valorization of the resulting products, and specifically the liquid product fraction: bio-oil. ${ }^{5-9}$

Bio-oil is a highly complex and unstable mixture of oxygenated components, which can be classified into five main groups: (i) hydroxyaldehydes, (ii) hydroxyketones, (iii) sugars, (iv) carboxylic acids and (v) phenolics. ${ }^{10}$ In addition, it has a high water (20-30 wt $\%$ ) and oxygen content which, together with its viscosity, acidity and corrosiveness render bio-oil unsuitable for higher-value applications, like the production of biofuels or biochemicals. ${ }^{11,12}$ One of the main challenges for bio-oil application is to accurately analyse its composition and the evolution/conversion of these refractory bio-oil species in order to adequately progress in the catalyst selection, kinetic modeling and process optimization.

Among all bio-oil characterization techniques, gel permeation chromatography (GPC) is known to provide a full overview of the molecular weight distribution of oxygenated mixtures, but also require to be combined with mass spectrometry (MS) techniques for detailed insights. ${ }^{13}$ Traditional gas chromatography (GC) has also been applied for the quantitative analysis of bio-oils. However, this technique is heavily limited by the volatility of the sample and often a large fraction of the liquid remains "invisible". ${ }^{14}$ Two-dimensional GC (GC $\left.\times \mathrm{GC}\right)$ can significantly improve the chromatographic resolution of conventional GC, by providing richer structural information. ${ }^{15,16}$ More advanced techniques like nuclear magnetic resonance (NMR), high performance liquid chromatography (HPLC) or Fourier transformed infrared (FTIR) spectroscopy are known to provide valuable information on the quantification of specific functional groups in bio-oils. ${ }^{17}$

Ultrahigh-resolution Fourier transform ion cyclotron resonance mass spectrometry (FT-ICR/MS) has the capability of making a great impact in the analysis of highly complex and heavy feedstocks

like heavy crude oil-derived mixtures, ${ }^{18,19}$ or oxygenated streams. ${ }^{13,20}$ Through this technique, the analysis of highly polar species (like those in bio-oil) is plausible using electrospray ionization (ESI), while the non-polar hydrocarbons and neutral phenolics are preferentially ionized through 
atmospheric pressure photoionization ((+)APPI). Palos et al. ${ }^{21}$ have applied (+)APPI FT-ICR/MS for elucidating the activity of a series of hydrotreatment catalysts on the upgrading of a light cycle oil and scrap tire oil (LCO/STO) blend. Al Jamri et al. ${ }^{22}$ have also reported the power of molecularlevel FTICR characterization for aiding in the prediction of bulk properties of bio-oil and heavy crude oil blends. In addition, FT-ICR/MS has been pointed as a very powerful tool for the molecular elucidation of the carbonaceous structures responsible for catalyst deactivation. ${ }^{23}$ Palacio Lozano et al. ${ }^{24}$ applied FT-ICR/MS for the characterization of a bio-crude, derived from the fast pyrolysis of biomass, as well as its esterified product. This work nicely exemplifies the use of different ionization techniques to obtain complementary compositional information with FTICR/MS. In line with these works, Ware et al. ${ }^{25}$ used (+)APPI FT-ICR/MS for demonstrating the capacity of hydrotreatment for drastically reducing the carbon number distribution and oxygen content from an oak-derived biocrude. Michailof et al. ${ }^{26}$ have reviewed the analytical techniques for bio-oil characterization indicating that a multi-technique approach is required to assess the full composition of this complex mixture, while Usman et al. ${ }^{27}$ indicate that similar approaches are required for the bio-oils derived from biomass liquefaction.

Hydrodeoxygenation (HDO) is the most studied route for bio-oil upgrading for both the production of fuels and/or chemicals, ${ }^{28-30}$ but remains challenging when it comes to improving catalyst stability and design. ${ }^{31,32}$ Noble metal-based catalysts are known to be very active towards HDO even at mild conditions, and hence, they are mainly applied for hydrocracking purposes. ${ }^{29,33-35} \mathrm{On}$ the other hand, transition metal-based catalysts have been the most studied for HDO purposes, given their milder hydrotreating activity, as well as their cheaper price ${ }^{36,37}$ On the side of supports, highly porous activated carbon has proven enhanced stability in this process. ${ }^{29,38,39}$ Typically, the liquid product of bio-oil consists of an aqueous and an organic fraction and, while the aqueous fraction is easy to characterize, the organic fraction presents high concentrations of heavily functionalized unsaturated species, which require the use of the aforementioned analytical techniques for its complete characterization. Assessing the conversion of the heaviest bio-oil fraction, which contains the most refractory compounds is also of paramount importance in order to achieve an optimized catalyst design, and unravel the kinetics involved.

In this work, we have developed a methodology, consisting on the utilization of a range of analytical techniques, to characterize the totality of the feed and the products in the HDO of a raw bio-oil obtained from the fast pyrolysis of black poplar. The methodology requires to separate the 
product fractions and systematically correlate the results across the different techniques. Besides microGC, GC/MS, GC×GC/MS, EA, GPC, Karl-Fischer and TG-TPO, we have used FT-ICR/MS with (-)ESI and (+)APPI as a powerful tool to assist in the full characterization of the organic product fraction. We have used this systematic approach to compare the catalytic performance of a set of promising HDO catalysts: three activated carbon supported PtPd, NiW and CoMo catalysts mixed with a HZSM-5 zeolite (for enhancing the production of phenolics and aromatics). ${ }^{37}$ The main goals of this work are: (i) a thorough characterization of the raw bio-oil and its hydrodeoxygenated products including all phases and the heaviest species, (ii) fully describing the chemistry behind the transformations of oxygenates and aromatics, (iii) establishing a diagram with the preferential reactivity of products on the basis of their oxygen and carbon number, and (iv) describing the multiple reaction pathways occurring simultaneously in the process and ways to quantify them. A detailed catalyst comparison would require further experimentation using the analytical workflow described here.

\section{Experimental}

\section{Catalyst synthesis and characterization}

Three phosphorus-containing activated carbon (ACP) catalysts have been used. The ACP supports were prepared through chemical activation of olive stone. Firstly, olive stones were impregnated with $\mathrm{H}_{3} \mathrm{PO}_{4}$ (85 wt\%, $3 \mathrm{~g}$ of $\mathrm{H}_{3} \mathrm{PO}_{4}$ per $\mathrm{g}$ of precursor) and subsequently activated under a $\mathrm{N}_{2}$ flow

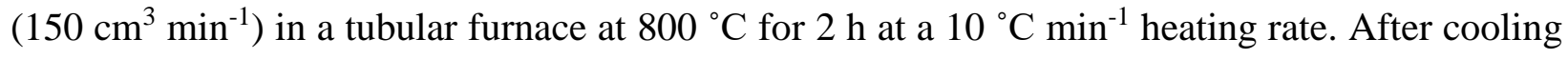
down, the activated carbon was washed with distilled water at $60{ }^{\circ} \mathrm{C}$ until complete removal of phosphate in the eluent, and finally dried in a vacuum drier at $100{ }^{\circ} \mathrm{C}$ for $12 \mathrm{~h}$. The ACP was then sieved to a particle size of $100-300 \mu \mathrm{m}$. The metallic phases were simultaneously incorporated in the catalysts by incipient wetting of aqueous solutions of the precursor salts slightly acidified with $\mathrm{HCl}$. Specifically, the metal content and precursor salts for the bimetallic catalysts were: (i) Pt (1 wt $\%$ ) and $\mathrm{Pd}(0.5 \mathrm{wt} \%)$, impregnated using $\mathrm{HPtCl}_{6} 6 \mathrm{HCl}$ and $\mathrm{PdCl}_{2}$ as precursors, (ii) $\mathrm{Ni}(5 \mathrm{wt} \%$ ) and $\mathrm{W}(2 \mathrm{wt} \%)$, impregnated using an aqueous solution of $\mathrm{Ni}\left(\mathrm{NO}_{3}\right) 6 \mathrm{H}_{2} \mathrm{O}$ and $\left(\mathrm{NH}_{4}\right)_{6} \mathrm{~W}_{7} \mathrm{O}_{24} 6 \mathrm{H}_{2} \mathrm{O}$, and (iii) $\mathrm{Co}(3 \mathrm{wt} \%)$ and $\mathrm{Mo}(12 \mathrm{wt} \%)$, impregnated using an aqueous solution of $\mathrm{Co}\left(\mathrm{NO}_{3}\right)_{2} 6 \mathrm{H}_{2} \mathrm{O}$ and $\left(\mathrm{NH}_{4}\right)_{6} \mathrm{Mo}_{7} \mathrm{O}_{24} 4 \mathrm{H}_{2} \mathrm{O}$. All precursor salts were provided by Sigma-Aldrich. The final catalysts were heat-treated in a tubular furnace under a $\mathrm{N}_{2}$ atmosphere $\left(150 \mathrm{~cm}^{3} \mathrm{~min}^{-1}\right)$ at $400{ }^{\circ} \mathrm{C}$ for $4 \mathrm{~h}$. The obtained catalysts have been designated as PtPd, NiW and CoMo, respectively. 
The commercial HZSM-5 zeolite (HZ) with a Si/Al of 140 was provided by Zeolyst International in its ammonium form. After drying at $100{ }^{\circ} \mathrm{C}$ for $6 \mathrm{~h}$, the zeolite was calcined in a muffle oven at $575{ }^{\circ} \mathrm{C}$ for $2 \mathrm{~h}$. The zeolite was finally tableted and sieved to a particle size of $300-600 \mu \mathrm{m}$. The physical mixture of metal supported on carbon and zeolite $(80-20 \mathrm{wt} \%)$ have been designated as PtPdHZ, NiWHZ and CoMoHZ.

The porous structure of the catalysts was analyzed by $\mathrm{N}_{2}$ adsorption-desorption at $-196{ }^{\circ} \mathrm{C}$ in a Micromeritics ASAP 2020 unit. Samples (ca. $100 \mathrm{mg}$ ) were vacuum degassed at $150{ }^{\circ} \mathrm{C}$ for $8 \mathrm{~h}$ prior to analysis. From the isotherm data, the specific surface $\left(\mathrm{S}_{\mathrm{BET}}\right)$ was calculated applying the Brunauer-Emmett-Teller equation. The micropore volume $\left(\mathrm{V}_{\text {micro }}\right)$ was calculated using the $t$-plot method. On the other hand, the average pore diameter $\left(\mathrm{d}_{\text {pore }}\right)$ was estimated by applying the BJH method. The acidic properties of the catalysts were determined from temperature programmed desorption (TPD) of tert-butylamine $(t \mathrm{BA})$ in a Setaram DSC thermogravimetric-calorimeter analyser coupled online with a Balzers Thermostar Quadstar 422 mass spectrometer. Samples were stripped under a He flowrate at $550{ }^{\circ} \mathrm{C}$ prior to isothermal adsorption of $t \mathrm{BA}$ at $100{ }^{\circ} \mathrm{C}$. The TPD was conducted up to $500{ }^{\circ} \mathrm{C}$ at a $5{ }^{\circ} \mathrm{C} \mathrm{min}^{-1}$ rate. The recorded mass during TPD was the one associated with butene $(\mathrm{m} / \mathrm{z}=56)$. X-ray photoelectron spectroscopy (XPS) was used for studying the chemical surface composition and elemental identity of the catalysts in a 5700C model Physical Electronics apparatus with $\mathrm{MgK} \alpha$ radiation $(1253.6 \mathrm{eV})$. The $\mathrm{C} 1 \mathrm{~s}$ peak was located at $284.5 \mathrm{eV}$ and it was used as reference to locate the other peaks. Fitting of XPS peaks was done by least squares using Gaussian-Lorentzian peak shapes.

\section{Hydrodeoxygenation unit}

The bio-oil hydrodeoxygenation runs were conducted in a lab-scale fixed bed reactor described in detail elsewhere, ${ }^{40}$ and under the following conditions: $450{ }^{\circ} \mathrm{C}$; 65 bar; space time, $0.15 \mathrm{~g}_{\text {cat }} \mathrm{h}$ g biooil $^{-1} ; 90 \mathrm{~cm}^{3} \mathrm{~min}^{-1} \mathrm{H}_{2}$ and time on stream, 0-6 h. After mild stirring, bio-oil was fed to the reaction box using a Gilson 305 HPLC piston pump without any previous dilution, and before entering the catalytic reactor it was pre-heated within the reaction box at $100{ }^{\circ} \mathrm{C}$, and pre-mixed with $\mathrm{H}_{2}$. The catalyst was loaded in the reactor following the protocol described elsewhere. ${ }^{41}$ Mixtures of ACPbased (80 wt $\%$ ) and HZSM-5 zeolite (20 wt\%) were tested, and the space time refers to the sum of both catalysts. Prior to the reaction, the catalyst mixtures were reduced at $400{ }^{\circ} \mathrm{C}$ for $4 \mathrm{~h}$ under a gas flowrate of $30 \mathrm{~cm}^{3} \mathrm{~min}^{-1} \mathrm{H}_{2}$ and $50 \mathrm{~cm}^{3} \mathrm{~min}^{-1} \mathrm{~N}_{2}$. 


\section{Bio-oil and product analysis}

The raw bio-oil was produced by fast pyrolysis of black poplar sawdust in a pilot plant equipped with a Conical Spouted Bed Reactor (CSBR) which can process up to $25 \mathrm{~kg} \mathrm{~h}^{-1} .{ }^{42}$ The elemental analysis (CHNS) of the raw bio-oil and the organic product oils was performed in a vario MICRO Cube V1.7 instrument (Elemental Analysensysteme GmbH, Hanau, Germany). The oxygen content was calculated by difference. The amount of water in the bio-oil was quantified through Karl-Fischer titration in a Metrohm830 KF Titrino plus apparatus, while its chemical composition was analyzed by means of gas chromatography in a Shimadzu GC-MS QP2010 unit. The molecular weight distribution of the raw bio-oil was obtained through gel permeation chromatography (GPC) in an Agilent 1260 Multi-Detector GPC/SEC system, provided with two PLgel MiniMIX-C columns (4.6 x $250 \mathrm{~mm}, 5 \mu \mathrm{m})$. Tetrahydrofuran (THF) was used as a mobile phase. Prior to analysis, the sample was diluted in THF in a sample:THF mass ratio of 1:10.

An overview of the HDO reaction product characterization is provided in Scheme 1. Gases were collected and analyzed in an Agilent 3000A microGC, provided with 4 channels: (i) a molecular sieve to separate the permanent gases $\mathrm{H}_{2}, \mathrm{O}_{2}, \mathrm{~N}_{2}, \mathrm{CH}_{4}$ and $\mathrm{CO}$; (ii) a Porapak Q to separate $\mathrm{CO}_{2}$ and water; (iii) a $\mathrm{Al}_{2} \mathrm{O}_{3}$ to separate $\mathrm{C}_{2}-\mathrm{C}_{5}$ hydrocarbons; and (iv) a Stabilwax to separate $\mathrm{C}_{6}-\mathrm{C}_{8}$ hydrocarbons, methanol and BTX aromatics. Liquid reaction products consisted of two easily separable aqueous and organic phases, which were individually analyzed. The organic product

phase was analyzed by two-dimensional gas chromatography in an Agilent 7890A unit coupled online with an Agilent 5975C series mass spectrometer (GC $\times \mathrm{GC}-\mathrm{MS})$. Organic products were also analyzed by means of GPC in the same setup previously specified for raw bio-oil. The water content and composition of the aqueous product phase were analyzed by means of Karl-Fischer titration and GC-MS characterization, respectively, in the previously detailed Shimadzu apparatus. Extended details on the GC units and methodologies can be found in the Supplementary Information. 


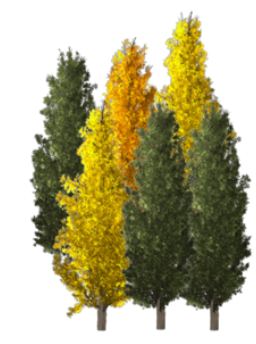

Black poplar
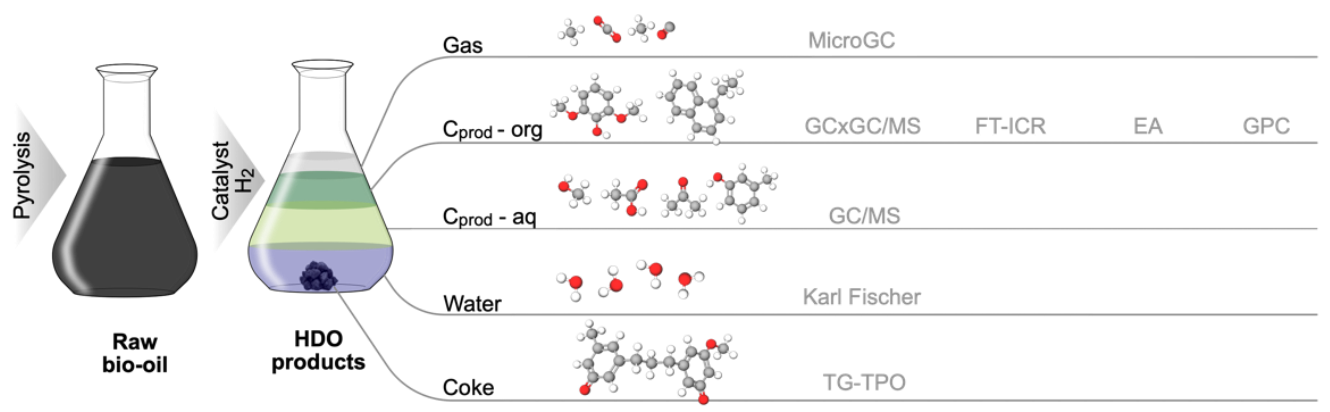

Scheme 1. Overview of the reaction media characterization

The liquid carbon product and water yields were defined by Eq. 1

$Y_{\text {i,wet bio-oil }}=\frac{F_{\mathrm{i}}}{F_{\text {total bio-oil }}} 100$

where $F_{\mathrm{i}}$ and $F_{\text {total bio-oil }}$ are the mass flows of the product fractions and the total bio-oil feed, respectively. On the other hand, the different hydrocarbon and oxygenated product lumps were grouped as follows: oxygenates (acetic acid, methanol, acetone), alkanes, ketones, phenol, phenolics, 1-ring aromatics $\left(\mathrm{A}_{1}\right)$, 2-ring aromatics $\left(\mathrm{A}_{2}\right)$ and other oxygenates (acids and esters).

The organic liquid product fraction was also analyzed by means of FT-ICR/MS on a 12-T Bruker SolariX XR FT-ICR mass spectrometer (Bruker Daltonics, Bremen, Germany), equipped with a dynamically harmonized ICR cell (Paracell) and an Apollo-II atmospheric pressure ion source, operating in both negative-ion ESI and positive-ion APPI modes. For the MS experiments, the samples were diluted to a stock solution concentration of $1 \mathrm{mg} \mathrm{mL}{ }^{-1}$ with toluene-methanol mixture $(50: 50 \mathrm{v} / \mathrm{v})$. Then the samples were dissolved to a concentration of $50 \mathrm{mg} \mathrm{mL}^{-1}$ in methanol for the (-)ESI and in toluene-methanol (30:70 v/v) for the (+)APPI measurements. All the used solvents were HPLC grade. The data were internally recalibrated with respect to the known $\mathrm{O}_{\mathrm{x}}$ species. The molecular formula assignments were carried out with PetroOrg IS-18.0.3 software (Omics LLC, Tallahassee, Florida, US). The MS experiments, data processing and molecular formula assignments have been described elsewehere. ${ }^{21}$ The DBE number, which measures the degree of unsaturation in a molecule from its estimated molecular formula, is defined by Eq. 2:

$D B E\left(C_{c} H_{h} N_{n} O_{o} S_{s}\right)=c-\frac{h}{2}+\frac{n}{2}+1$ 
The coke deposited in the used catalysts was quantified by combining thermogravimetric techniques with a temperature-programmed oxidation (TG-TPO) in a TA Instruments TGA Q5000 IR apparatus. Prior to analysis, samples (ca. $5 \mathrm{mg}$ ) were subjected to a stripping pre-treatment under a $\mathrm{N}_{2}$ atmosphere $\left(100 \mathrm{~mL} \mathrm{~min}^{-1}\right)$ at $450{ }^{\circ} \mathrm{C}$ in order to remove organic adsorbed species. TGTPO analyses were conducted under a continuous air flow $\left(100 \mathrm{~cm}^{3} \mathrm{~min}^{-1}\right)$ applying a ramp of 5 ${ }^{\circ} \mathrm{C} \min ^{-1}$ up to $700{ }^{\circ} \mathrm{C}$, which ensures total combustion of the formed coke and the carbon support. The relative amounts of each coke type (thermal lignin, TL; and catalytic coke, CK) were calculated through a Lorentzian deconvolution of the DTG-TPO profiles using a MATLAB ${ }^{\circledR}$ routine. The coke yield was calculated from the TG-TPO analysis results and defined by Eq. 3 as:

$Y_{\text {Coke }}=\frac{\frac{x_{\text {coke }}}{x_{A C P}} m_{A C P}}{m_{\text {bio-oil }}}$

where $m_{A C P}$ is the ACP-supported catalyst mass in the reactor $(0.4 \mathrm{~g}), x_{\text {coke }}$ is the total coke fraction (Thermal lignin, TL; and catalytic coke, CK) deconvoluted from the DTG-TPO curve, ${ }^{37} x_{A C P}$ is the remaining support fraction and $m_{\text {bio-oil }}$ is the mass of bio-oil fed hourly. Finally, the gas yield was computed by difference with the rest of all yields.

\section{Conversions}

Cumulative HDO and hydrotreatment/hydrocracking (HT/HC) conversions have been defined for further assessment of the catalysts. The conversions of a given oxygenate or hydrocarbon achieved in the different organic product oils with respect to the same fractions in the raw bio-oil feedstock has been defined by Eq. 4 and Eq. 5, as follows:

Cumulative HDO conversion $(\%)=\frac{C_{O_{X+, b i o-o i l}}-C_{O_{X+, \text { product oil }}}}{C_{O_{X+, \text { bio-oil }}}} 100$

Cumulative HT/ HC conversion (\%) $=\frac{C_{C_{X+, \text { bio-oil }}}-C_{C_{X+, \text { product oil }}}}{C_{C_{X+, \text { bio-oil }}}} 100$

where $\mathrm{C}_{\mathrm{Ox}+}$ and $\mathrm{C}_{\mathrm{Cx}}$ are the concentrations of the fractions with $\mathrm{x}+$ oxygen and carbon atoms, respectively.

\section{Results}

Raw bio-oil properties 
Table 1 lists some of the main properties and a detailed composition of the raw bio-oil, as obtained from Karl-Fischer, elemental analysis, GC/MS, and (+)APPI and (-)ESI FT-ICR/MS techniques combined. Besides a water content of $49.0 \mathrm{wt} \%$, the elemental composition of the raw bio-oil on a dry basis consists of a $35.5 \mathrm{wt} \%$ oxygen, together with $57.4 \mathrm{wt} \%$ carbon and a smaller amount of hydrogen of $5.9 \mathrm{wt} \%$, with little nitrogen being detected (1.2 wt\%). Sulfur is not reported because it was below the detection limit of the setup. Through GC/MS analysis of the raw bio-oil, the main detected components were acetic acid (23.5\%) and levoglucosan $(24.0 \%)$, with lower amounts of acids and esters (9.5\%), ketones (8.5\%), phenols (13.0\%) and alcohols (6.5\%). Levoglucosan is a very relevant product and certain interest lays on its separation, purification and commercialisation. ${ }^{43}$ Besides levoglucosan, other phenols are also very attractive to be targeted for bio-oil. ${ }^{44}$ The limitations of the GC-MS methodology for efficiently characterizing such an intrinsically complex oxygenated mixture as raw bio-oil are evidenced from the relatively light and low molecular weight compounds identified through this technique, in contrast to the high average molecular weight compounds known to be present such oils, specifically in the pyrolytic lignin fraction. ${ }^{45,46} \mathrm{GPC}$ analyses (data discussed in further detail in coming sections) revealed that the average molecular weight of the raw bio-oil was of $460 \mathrm{~g} \mathrm{~mol}^{-1}$, indicating that there is a remarkable bio-oil fraction that remains invisible to GC/MS. (+)APPI FT-ICR/MS analysis detected a clear majority of oxygenated components (79.2\%) together with a significant content of $\mathrm{N}_{Y} \mathrm{O}_{X}$ species $(16.3 \%)$ and smaller amounts of hydrocarbons $(4.5 \%)$. Similarly, $80.7 \%$ of oxygenates and $14.8 \% \mathrm{NYO}_{\mathrm{X}}$ species were detected through (-)ESI FT-ICR/MS, with a $4.5 \%$ of sulphur-containing $\mathrm{O}_{X} \mathrm{~S}_{Z}$ species, but no hydrocarbons. These results reveal the different selectivity of both ionization methods towards different component groups. While (-)ESI selectively ionizes polar heteroatomic species, $(+)$ APPI is capable of a better ionization of nonpolar compounds. $^{21,47}$

Table 1. Main physico-chemical properties of the raw bio-oil

$\begin{array}{lc}\text { Density }\left(\mathrm{g} \mathrm{cm}^{-3}\right) & 1.1 \\ \text { Water content }(\mathrm{wt} \%) & 49.0 \\ \text { Elemental analysis (wt\%, on a dry basis) } & 57.4 \pm 0.1 \\ \mathrm{C} & 5.90 \pm 0.03 \\ \mathrm{H} & 1.20 \pm 0.01 \\ \mathrm{~N} & 35.50 \pm 0.1 \\ \mathrm{O} & \end{array}$

GC/MS, composition (\% of the volatile fraction) 
$\begin{array}{lr}\text { Acids and esters } & 9.5\end{array}$

$\begin{array}{lr}\text { Acetic acid } & 23.5\end{array}$

Aldehydes $\quad 4.8$

$\begin{array}{lr}\text { Ketones } & 8.7\end{array}$

$\begin{array}{ll}\text { 1-hydroxy-2-propanone } & 7.0\end{array}$

$\begin{array}{lc}\text { Phenols } & 13.0\end{array}$

$\begin{array}{ll}\text { Alcohols } & 6.5\end{array}$

$\begin{array}{ll}\text { Ethers } & 2.0\end{array}$

Levoglucosan $\quad 24.0$

Non identified $\quad 1.0$

(+)APPI FT-ICR/MS, relative abundance (\%)
Hydrocarbons

$\begin{array}{lc}\mathrm{O}_{\mathrm{X}} \text { species } & 79.2\end{array}$

$\mathrm{N}_{Y}$ species $\quad 0.2$

$\mathrm{N}_{\mathrm{Y}} \mathrm{O}_{\mathrm{X}}$ species $\quad 16.1$

(-)ESI FT-ICR/MS, relative abundance (\%)

Hydrocarbons $\quad 0$

$\begin{array}{lr}\mathrm{O}_{\mathrm{X}} \text { species } & 80.7\end{array}$

$\mathrm{N}_{\mathrm{Y}} \mathrm{O}_{\mathrm{X}}$ species $\quad 14.8$

$\mathrm{O}_{\mathrm{X}} \mathrm{S}_{\mathrm{Z}}$ species $\quad 4.5$

The color-coded DBE vs. carbon number plot corresponding to the oxygenates present in bio-oil (see Figure S1) and measured through (-)ESI FT-ICR/MS reveals molecules within a wide range of carbon numbers between $\mathrm{C}_{5}-\mathrm{C}_{40}$ and $\mathrm{DBE}$ from 0 to 22. A clear high concentration cluster appears at $\mathrm{C} \#=6-12$ and $\mathrm{DBE}=1-7$, indicating a very prominent presence of the monomers derived from the partial depolymerization of lignin in biomass, namely coumaryl $(\mathrm{C} \#=9, \mathrm{DBE}=$ 5), coniferyl $(\mathrm{C} \#=10, \mathrm{DBE}=5)$ and sinapyl alcohols $(\mathrm{C} \#=11, \mathrm{DBE}=5)$. In addition, an important content of phenolic-based structures ( $\mathrm{DBE}=4$, i.e. phenol, catechol, guaiacol, syringol) should also be expected in the mixture, with a high number of alkyl substituents.

Properties of the catalysts

The properties of the fresh ACP-based catalysts and the calcined HZSM-5 zeolite are summarized in Table 2. All carbon-based catalysts present a high specific surface area and a well-developed micropore structure, accounting for $46-56 \%$ of the total pore structure in all the catalysts. More specifically, the BET surface area of the PtPd catalyst $\left(1380 \mathrm{~m}^{2} \mathrm{~g}_{\mathrm{cat}}{ }^{-1}\right)$ was significantly higher than those of the NiW and CoMo catalysts (755-885 $\left.\mathrm{m}^{2} \mathrm{~g}_{\mathrm{cat}}{ }^{-1}\right)$, attributed to the significantly lower metal loading. The lowest metal concentrations were those of the PtPd catalyst $(1.2 \mathrm{wt} \%$ and 0.5 $\mathrm{wt} \%$ for Pt and Pd, respectively), followed by the $\mathrm{NiW}(4.5 \mathrm{wt} \% \mathrm{Ni}, 1.7 \mathrm{wt} \% \mathrm{~W})$, while the CoMo catalyst presents the highest loadings with $4.9 \mathrm{wt} \%$ Co and $12.5 \mathrm{wt} \%$ Mo. The total acidity of the 
carbon-supported catalysts ranged between $0.28-0.42 \mathrm{mmol}_{t \mathrm{BA}} \mathrm{g}_{\mathrm{cat}}{ }^{-1}$, while the acidity of the Z140 zeolite was of $0.41 \mathrm{mmol}_{t \mathrm{BA}} \mathrm{g}_{\mathrm{cat}}{ }^{-1}$. These unusually high acidity values measured for the ACPbased catalysts are due to the phosphorus-containing acidic functionalities formed during the chemical activation stage, which are thermally stable -C-O-P-OH and -C-P-OH structures which provide the support with enhanced Brønsted type acidity. ${ }^{29}$ Nonetheless, the highest acidic strength is that of the zeolite, with $112 \mathrm{~kJ} \mathrm{~mol}_{t \mathrm{BA}}{ }^{-1}$.

Table 2. Properties of the fresh ACP-supported and the HZ zeolite catalysts

\begin{tabular}{|c|c|c|c|c|}
\hline & PtPd & $\mathrm{NiW}$ & CoMo & $\mathrm{HZ}$ \\
\hline \multicolumn{5}{|l|}{ Textural parameters } \\
\hline $\mathrm{S}_{\mathrm{BET}}\left(\mathrm{m}^{2} \mathrm{~g}_{\mathrm{cat}}{ }^{-1}\right)$ & 1380 & 886 & 755 & 485 \\
\hline$V_{\text {pore }}\left(\mathrm{cm}^{3} \mathrm{~g}_{\mathrm{cat}}{ }^{-1}\right)$ & 1.13 & 0.61 & 0.36 & 0.36 \\
\hline $\mathrm{V}_{\text {micropore }}\left(\mathrm{cm}^{3} \mathrm{~g}_{\text {cat }}{ }^{-1}\right)$ & 0.53 & 0.28 & 0.20 & 0.20 \\
\hline $\mathrm{d}_{\text {pore }}(\AA)$ & 58 & 56 & 74 & 74 \\
\hline \multicolumn{5}{|l|}{ Acidic properties } \\
\hline Total acidity $\left(\mathrm{mmol}_{t \mathrm{BA}} \mathrm{g}_{\mathrm{cat}}{ }^{-1}\right)$ & 0.38 & 0.28 & 0.43 & 0.41 \\
\hline Acidic strength $\left(\mathrm{kJ} \mathrm{mol}_{t} \mathrm{BA}^{-1}\right)$ & 68 & 70 & 55 & 112 \\
\hline \multicolumn{5}{|l|}{ XPS surface concentration } \\
\hline $\mathrm{Pt}(\mathrm{wt} \%)$ & 1.2 & - & - & - \\
\hline $\mathrm{Pd}(\mathrm{wt} \%)$ & 0.5 & - & - & - \\
\hline $\mathrm{Ni}(\mathrm{wt} \%)$ & - & 4.5 & - & - \\
\hline $\mathrm{W}(\mathrm{wt} \%)$ & - & 1.7 & - & - \\
\hline $\mathrm{Co}(\mathrm{wt} \%)$ & - & - & 4.9 & - \\
\hline Mo (wt\%) & - & - & 12.5 & - \\
\hline
\end{tabular}

\section{Preliminary catalyst performance}

The main product yields (as defined by Eq. 1) obtained using the different catalyst combinations are displayed in Figure 1a. In all cases water was the main product with overall yields of 41-56 $\mathrm{wt} \%$, formed as an end product of most HDO reactions. In the case of the PtPdHZ and CoMoHZ catalysts, the gas product lump was secondary, with lower amounts being formed in the case of the NiWHZ catalyst (18.8 wt\%), indicating the lower cracking capacity of this catalyst. ${ }^{37}$ Both the overall lower acidity of the NiWHZ catalyst, as well as the lower hydrogenation activity of its metallic phase, play a synergistic role towards limiting cracking reactions that lead to higher gas product formation. ${ }^{48}$ On the other hand, gas formation was prominent for the PtPdHZ catalyst (33.7 $\mathrm{wt} \%$ ), more active on hydrocracking reactions, decarbonylation and decarboxylation. This higher 
activity results detrimental for the production of liquid carbon products, accounting for a total of $12.2 \mathrm{wt} \%$ using the PtPdHZ catalyst, while the NiWHZ and CoMoHZ catalysts provided identical total liquid product yields of $24.1 \mathrm{wt} \%$, with $15.0 \mathrm{wt} \%$ and $15.7 \mathrm{wt} \%$ organic product yields, respectively. Coke formation is the highest for the $\mathrm{CoMoHZ}$ catalyst (6.8 wt\%), which might be indicative of the presence of more condensed and oxygenated coke precursors in the reaction medium in contrast to the NiWHZ catalyst (which provides equal carbon product yields, but less coke). The higher activity of noble metal-based catalysts towards hydrocracking reactions (C-C bond breakage) generally acts in detriment of interesting platform chemical formation. ${ }^{37}$ This behaviour of noble metal-based catalyst in contrast to transition metals was previously highlighted by Ardiyanti et al. ${ }^{49}$ on the hydrotreatment of a bio-oil, where they obtained more aliphatic organic product phases with a higher $\mathrm{H} / \mathrm{C}$ ratio using zirconia-supported mono- and bimetallic noble metal catalysts instead of a CoMo catalyst. They also further demonstrated the milder activity of transition metals in a complementary study on Ni-based catalysts. ${ }^{50}$ Figueiredo et al. ${ }^{51}$ observed that by using a noble metal-based catalyst, high monomer yields in the organic products could be obtained from the hydrodeoxygenation of pyrolytic lignin, also with a higher deoxygenation degree, in line with our results.

The composition of the main gas products in Figure $1 \mathrm{~b}$ reveals a significant concentration of $\mathrm{CO}$ and $\mathrm{CO}_{2}$ (36.9 vol\% and $25.3 \mathrm{vol} \%$, respectively) using the PtPdHZ catalyst, which originate from decarbonylation $(\mathrm{CO})$ and decarboxylation $\left(\mathrm{CO}_{2}\right)$ reactions, mostly. $\mathrm{CO}_{2}$ was the predominant gas compound when using the NiWHZ catalyst (36.6 wt\%), formed as an end product of decarboxylation of acetic acid, which catalyticaly decomposes releasing $\mathrm{CO}_{2}$ and $\mathrm{CH}_{4}$ through a competitive decarboxylation-dehydration mechanism. ${ }^{37,52}$ On the other hand, given the lower HDO activity of the CoMoHZ catalyst, the concentration of $\mathrm{CH}_{4}(24.2 \mathrm{vol} \%)$ surpasses that of CO and $\mathrm{CO}_{2}$, indicating that less oxygen is being removed during $\mathrm{HDO}$ using this catalyst.

Details on the total coke content and CK/TL ratios (as obtained from the deconvolution of the DTG-TPO curves in Figure S2) are provided in Figure 1c. The highest coke deposition occurred with the CoMoHZ catalyst (84.4 wt\% in the deactivated catalyst), while the lowest amount of total coke was measured for the NiWHZ catalyst (35.0 wt\%). Despite its intermediate coke content of $53.0 \mathrm{wt} \%$, the PtPdHZ catalyst showed the highest CK/TL ratio of 5.5, which is 6-9 times higher than for the other two catalysts. The remarkably high total coke formation observed for the 
CoMoHZ catalyst can be explained from its lower HDO activity, which facilitates the enhancement of the coke formation mechanism from oxygenates. ${ }^{38,53}$ In addition, this lower deoxygenation activity also prevents TL from further reacting towards the formation of more condensed CK, which forms in a great proportion in the case of the PtPdHZ catalyst, given its very high HDO activity.

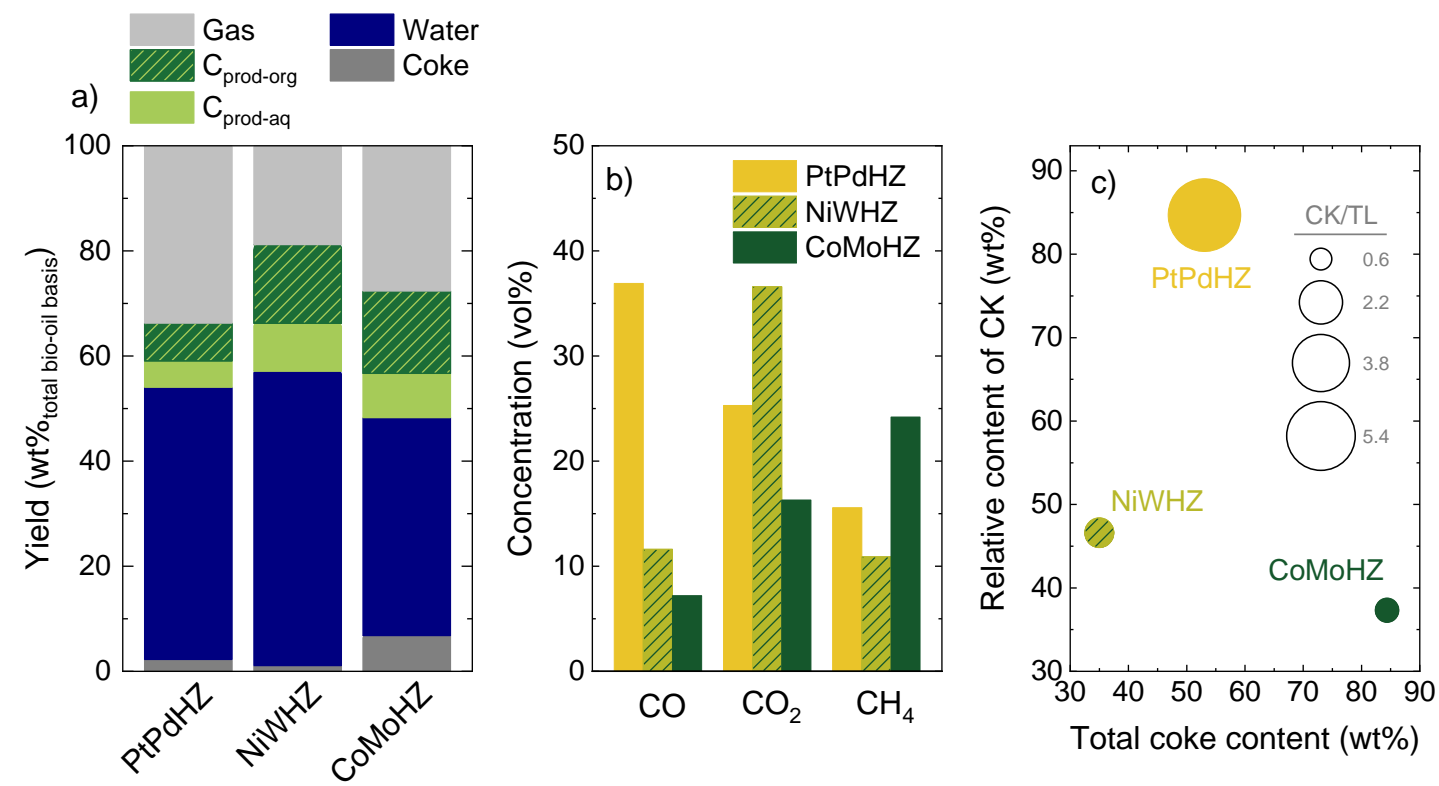

Figure 1. a) Main product distribution (wt \% on a wet bio-oil basis) obtained using the different catalysts, b) composition of the gas products and c) total coke content and characteristics.

As previously mentioned, liquid carbon products consist of two different product phases, an organic and an aqueous one, each containing oxygenates and hydrocarbons. ${ }^{38}$ The aqueous phase (Figure 2a), is composed mainly by oxygenates like methanol (which was the main one in the case of the PtPdHZ catalyst), acetic acid (main light oxygenated compound for the NiWHZ and CoMoHZ catalysts) and acetone. Additionally, significant amounts of phenol (9-18.7\%) and smaller amounts of alkylphenolic components (1.3-3.8 \%) were detected, consisting of mostly 2methylphenol and 3-methyl phenol. On the other hand, the composition of the organic fraction of the carbon products (Figure 2b) shows a clearly heavier nature. A predominant presence of aromatics (48.3\% 1-ring and $12.8 \%$ 2-ring) and paraffinic hydrocarbons (23.3\%) was measured in the case of the PtPdHZ catalyst. Phenol and phenolics were more abundant in the case of the NiWHZ and CoMoHZ catalysts (41.8\% and $45.8 \%$ in total, respectively), also showing a 
significantly lower amount of 1-ring aromatic components (23.3-27.3\%). A noticeable concentration of ketones of $23.7 \%$ was also measured for the NiWHZ catalyst. The highest proportion of heavy oxygenates in the product from the $\mathrm{CoMoHZ}$ catalyst would reinforce the premise for a faster coke formation rate due to their repolymerization. ${ }^{53,54} \mathrm{~A}$ more detailed chemical composition of the carbon products for all the catalyst combinations is provided in Table S1.

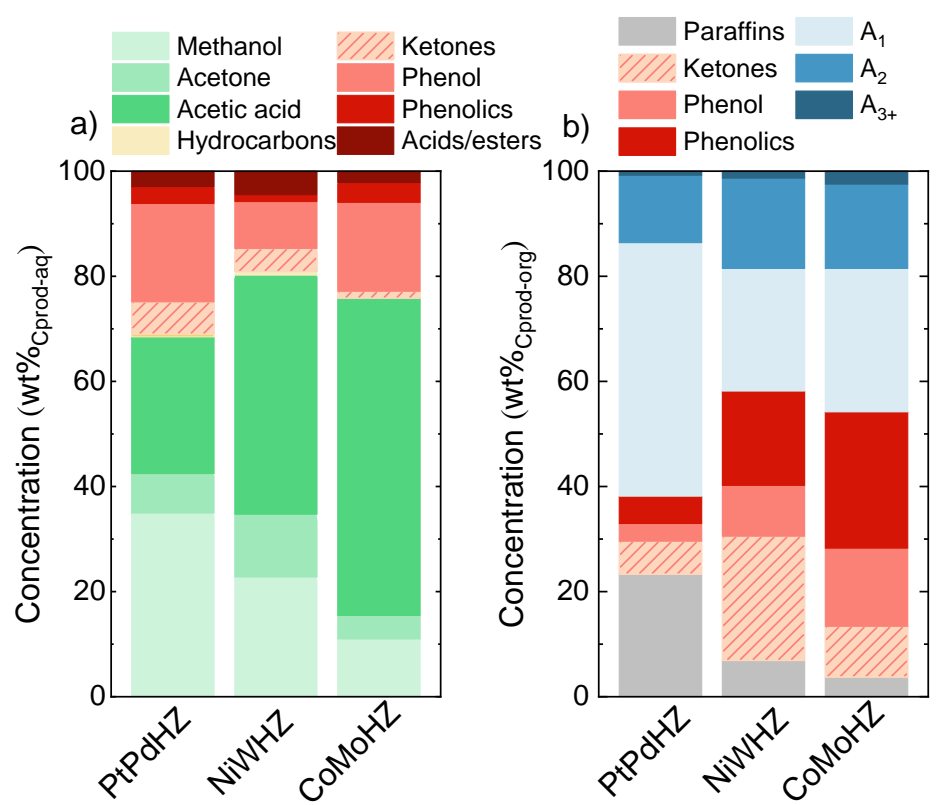

Figure 2. Concentration of the different lumps on the a) aqueous (measured by GC/MS) and b) organic product fractions (measured by $\mathrm{GC} \times \mathrm{GC} / \mathrm{MS}$ ) using the different catalysts.

Gel permeation chromatography (GPC) was applied in order to obtain the cumulative molecular weight distributions of the raw bio-oil feed as well as the organic product fractions derived from its HDO using the different catalyst combinations, as displayed in Figure 3a. This information allowed for estimating the percentage of the total organic product fraction that was potentially detectable through GCXGC/MS (results in Figure 2b), by establishing a "limit" chemical compound whose molecular weight was approximately the maximum value that the GC×GC/MS was capable of identifying. In this case, phenanthrene ( $\mathrm{M}_{\mathrm{w}}=178 \mathrm{~g} \mathrm{~mol}^{-1}$, see Table S1) was established as such. In the case of raw bio-oil, we estimate that only ca. $8 \mathrm{wt} \%$ of the mixture is GC-detectable, with an average molecular weight of $460 \mathrm{~g} \mathrm{~mol}^{-1}$. On the other hand, in the organic product oils, the volatile fraction increased up to 40.6, 54.0 and $70.7 \mathrm{wt} \%$ for the CoMoHZ, 
NiWHZ and PtPdHZ catalysts, corresponding to products with average molecular weights of 175 , 140 and $95 \mathrm{~g} \mathrm{~mol}^{-1}$, respectively. The overall lightest nature of the organic product obtained with the PtPdHZ catalyst, and the heaviest nature of those obtained with the CoMoHZ catalyst are in line with the results reported in Figure 1a and Figure 2, where their highest and lowest HDO activities are reported, respectively. Figure $2 \mathrm{~b}$ also shows a higher proportion of functionalized oxygenates being present in the CoMoHZ sample. The elemental composition (in a dry basis) of the organic product fractions is detailed in Figure 3b. The PtPdHZ product fraction contained the lowest oxygen amount $(6.4 \mathrm{wt} \%)$ with a predominance of carbon $(>85 \mathrm{wt} \%)$ in the mixture. On the other hand, the oxygen contents for the NiWHZ and CoMoHZ organic fractions was of 12.5 and $38.3 \mathrm{wt} \%$, respectively. Such high oxygen content for the CoMoHZ sample indicates a heavy functionalization degree of the oxygenated compounds present in it, in contrast to the NiWHZ oil.
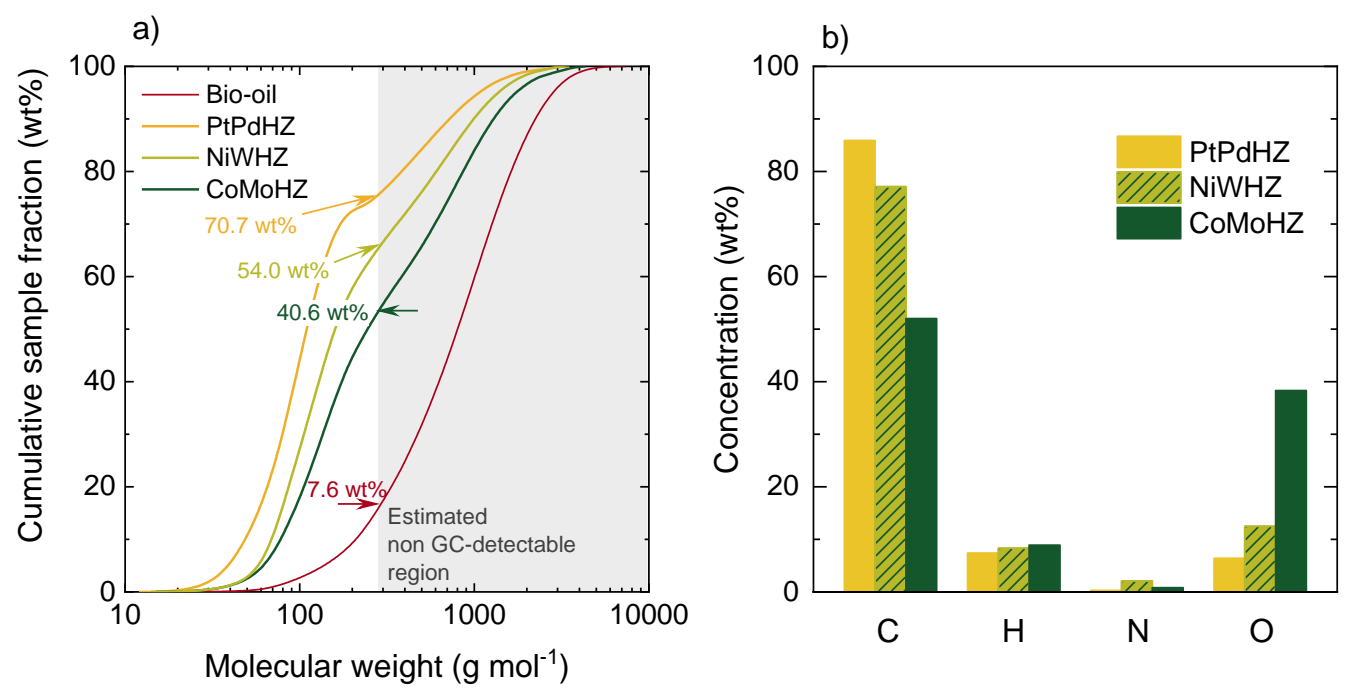

Figure 3. a) Cumulative molecular weight distribution and b) elemental composition for the organic product fractions as obtained using the different hydrodeoxygenation catalysts.

Based on all the previously presented results, we can conclude that the identification of the compounds in the aqueous liquid product fraction can be carried out efficiently and completely using GC techniques, given their overall low molecular weight. However, the organic liquid product fraction contains heavier and more refractory unsaturated compounds, which are the most resistant to their catalytic conversion by HDO. 


\section{Detailed characterization of the organic product fraction}

All samples (raw bio-oil and organic product fractions) were analyzed using two different ionization methods (namely (-)ESI and (+)APPI) in order to assess the differences in the obtained compound class distributions, displayed in Figure 4. As expected, a minor amount of hydrocarbons was detected in the raw bio-oil through (+)APPI (Figure 4a), with a predominance of $79.2 \%$ of pure oxygenates, and $14.8 \% \mathrm{~N}_{\mathrm{Y}} \mathrm{O}_{\mathrm{X}}$ species. On the other hand, the distribution for the organic product fractions revealed significantly higher amounts of hydrocarbons, with total abundances of 43.8, 24.3, 28.3 and \% for the PtPdHZ, NiWHZ, and CoMoHZ catalysts, respectively. $\mathrm{O}_{\mathrm{X}}$ species were the predominant ones in all the products with abundances $>40 \%$. While lower amounts of oxygenates were expected in the PtPdHZ sample based on its higher activity (see Figure 1a), a remarkably low amount of oxygenates was also observed in the NiWHZ sample, where high amounts of nitrogen-containing species were detected (34.2\%). Nonetheless, it should be taken into account that the ionization of this kind of polar species through (+)APPI presents low reliability and (-)ESI is preferred for their measurement. Furthermore, the overall polarity of the sample also conditions the efficient detection of certain species. Nonetheless, and despite its lower accuracy for polar compounds, (+)APPI is required in order to assess the nature of the hydrocarbon species of the organic products. Figure $4 \mathrm{~b}$ shows that the concentration of oxygenates through ()ESI can be as high as $95.5 \%$, for the CoMoHZ catalyst. Besides, through (-)ESI the amount of total detected species was lower in all cases in contrast to (+)APPI (see Figure S3). With no hydrocarbons being detected due to the very low efficiency of (-)ESI for ionizing these compounds, purely oxygenates $\left(\mathrm{O}_{\mathrm{X}}\right)$ were detected in an abundance above $80 \%$ in all cases. The lower abundance of oxygenates was that of PtPdHZ products $(81.3 \%)$, in line with the previously discussed results (see Figure 2b), increasing in the case of NiWHZ (90.7 \%) and even further for the CoMoHZ catalyst (95.6\%). Simultaneously, the content of $\mathrm{N}_{\mathrm{Y}} \mathrm{O}_{\mathrm{X}}$ and $\mathrm{O}_{\mathrm{X}} \mathrm{S}_{\mathrm{Z}}$ classes also decreases in the product samples in contrast to the raw bio-oil feed (14.8 and $4.5 \%)$, in the order PtPdHZ (11.2 and 3.0\%), NiWHZ (6.7 and 1.3\%) and CoMoHZ (3.5 and 1.0\%), respectively, and in concordance with their HDO activity trends in Figure 1 and Figure 2. 

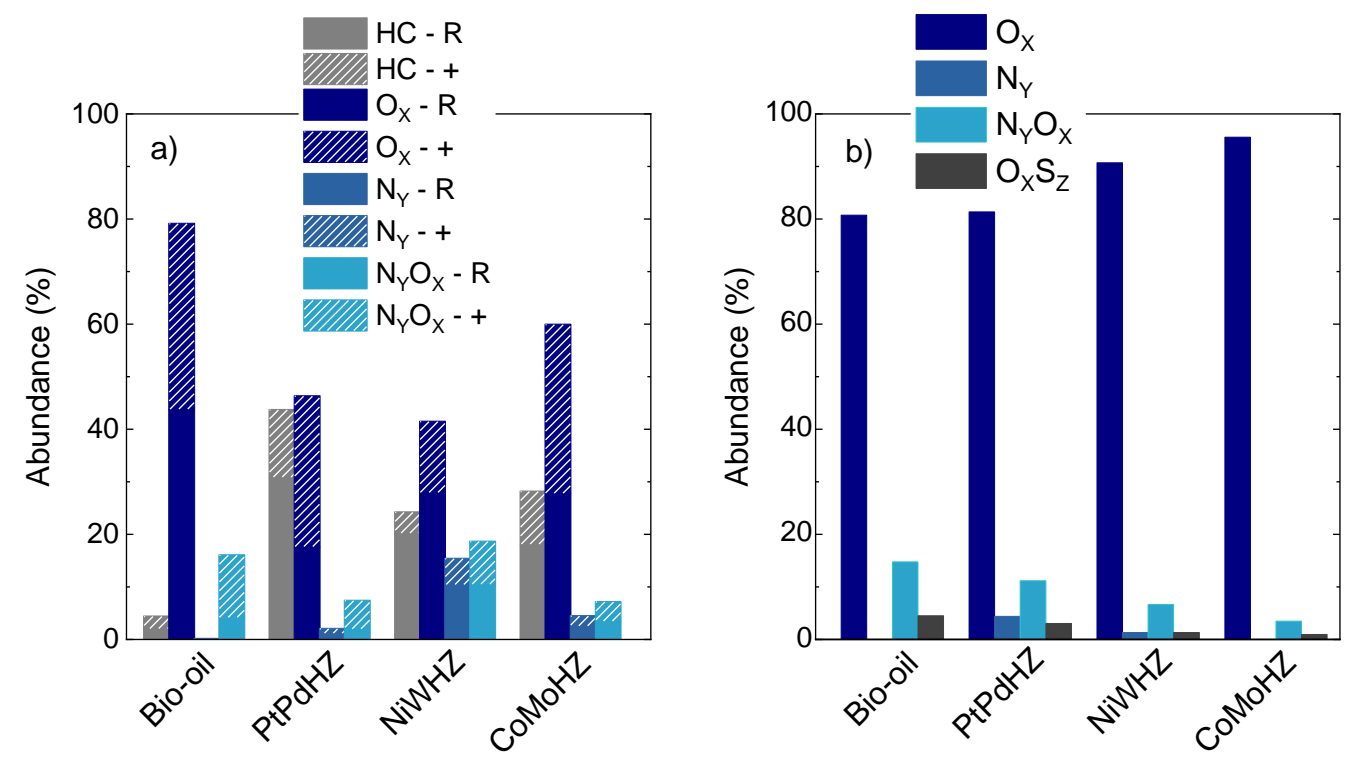

Figure 4. Relative abundance of the different compound classes in raw bio-oil and in the organic product fractions obtained using the different catalysts as measured by FT ICR/MS using a) $(+)$ APPI and b) (-)ESI.

\section{Oxygenates}

For a proper assessment of the composition of the different organic products, Figure 5 displays the distributions of the oxygenated species on a carbon number basis for the bio-oil feedstock and the organic product fractions, as measured from (-)ESI FT-ICR/MS. The lowest molecular carbon number that was possible to detect was of 5-6, which evidences the fact that these analyses are complementary to $\mathrm{GC} \times \mathrm{GC} / \mathrm{MS}$, which more efficiently detects compounds with carbon numbers of 2-10 (see Figure S4).

Raw bio-oil (Figure 5a) displays the most oxygenated nature (see also Table 2 and Figure S1), with a significant $\mathrm{O}_{10+}$ species of $26.4 \%$, and an overall $\mathrm{O}_{6+}$ species of $71.3 \%$. $\mathrm{O}_{6+}$ species are distributed in a carbon range number of 5-40, while lighter $\mathrm{O}_{2}-\mathrm{O}_{5}$ species have mostly between 2 to 20 carbon atoms. The overall distribution of oxygenates for bio-oil peaks in the carbon number range of $8-12$, which indicates that there is great abundance of bulky structures which originate from the partial depolymerization of lignin during the pyrolysis process. A more detailed assessment of each O-class through color-coded isoabundance plots for bio-oil (Figure S5) shows mostly homogeneous distributions of all O-classes in terms of their DBE number. While $\mathrm{O}_{1}$ species 
are undetected (Figure $\mathrm{S} 5 \mathrm{a}$ ) and the concentration of $\mathrm{O}_{2}$ species remains very low $(2.02 \%$, Figure $\mathrm{S} 5 \mathrm{~b}$ ), a high-concentration cluster is observed for $\mathrm{O}_{3}-\mathrm{O}_{10+}$ species (Figure S5c-j), also presenting an increasing carbon number range upon increasing the oxygen content in the molecule, as well as an increasing DBE number. The results corroborate that bio-oil predominantly consists of products from the degradation of lignin (species with 10-20 carbon atoms and DBE < 10), but also a higher molecular weight of $\mathrm{O}_{10+}$ species and higher DBE number. ${ }^{55,56}$

On the other hand, the organic product fractions showcase a significantly deoxygenated nature as well as a narrower carbon number distribution in all cases. The organic fraction produced with the PtPdHZ catalyst (Figure 5b) consists predominantly of $\mathrm{O}_{2}$ species (38.4\%), followed by $\mathrm{O}_{3}$ species $(29.0 \%)$ and lower amounts of $\mathrm{O}_{1}$ species $(13.7 \%) . \mathrm{O}_{1}$ species are assigned to phenol derivatives, and their concentration is higher in the carbon number range of 7 to 15 . The isoabundance plot for this class species (Figure S6a) also shows that these species predominantly present a DBE $=4$ (phenolic ring + a saturated chain), DBE $=5$ (phenolic ring + a mono-unsaturated chain) and DBE $=8$ (alkyl-substituted phenylphenol). The most concentrated $\mathrm{O}_{2}$ and $\mathrm{O}_{3}$ species are related to the presence of catechols and/or guaiacols $\left(\mathrm{O}_{2}\right)$ and syringols $\left(\mathrm{O}_{3}\right)$, also with long saturated chains attached, as evidenced from their high concentration at $\mathrm{DBE}=4$ in a wide carbon number range (Figure S6b,c). The remarkably high concentration of compounds with DBE $=1$ in the carbon number range of 10-20 for the $\mathrm{O}_{2}$ species indicates abundance of saturated fatty acids (i.e. lauric acid, palmitic acid, stearic acid), ${ }^{57-59}$ while (poly)unsaturated (DBE $=2-3$ ) acids (i.e. oleic acid, linoleic acid) are less abundant. Hydroxy/epoxy fatty acids $\left(\mathrm{O}_{3}\right)$ and diacids and/or dihydroxy fatty acids $\left(\mathrm{O}_{4}\right)$ with different saturation degree $(\mathrm{DBE}=1-3)$ are also present, but in a lesser extent. On the other hand, the compounds detected in the $\mathrm{O}_{4}, \mathrm{O}_{5}$ and $\mathrm{O}_{6}$ classes (Figure S6d-f), are mostly units derived from the depolymerization of the lignin fraction of biomass. ${ }^{60}$

A somewhat similar distribution is observed for the NiWHZ catalyst (Figure 5c), with a dominant presence of $\mathrm{O}_{2}(35.3 \%), \mathrm{O}_{3}(21.7 \%)$ and $\mathrm{O}_{4}(19.9 \%)$ species. The distribution of oxygen species on the basis of their carbon number is narrower in contrast to the PtPdHZ sample and centered in the 11-16 range. Consistent high concentration clusters have been observed in the NiWHZ product oil for $\mathrm{O}_{1}$ to $\mathrm{O}_{4}$ species (Figure S7a-d). These clusters are centered in the 10-15 carbon number range and $\mathrm{DBE}=4-9$, and their concentrations are higher for $\mathrm{O}_{2}$ species (Figure $\mathrm{S} 7 \mathrm{~b}$ ), the main one of all O-classes $(35.3 \%)$. In addition, a significant presence of mostly fatty acids was also 
detected in this class along $\mathrm{DBE}=4$. These results highlight the higher selectivity of the NiWHZ catalyst towards alkylmethoxyphenolic compounds in comparison to the PtPdHZ catalyst which leads to a higher hydrocarbon and acid formation. ${ }^{37,39}$

The distribution for the CoMoHZ sample (Figure 5d) shows a heavier and more oxygenated nature. In this case, $\mathrm{O}_{4+}$ species represent for $78.5 \%$ of the sample, with $\mathrm{O}_{4}$ species being the most abundant ones $(37.1 \%)$ and a carbon number distribution centered at $\# \mathrm{C}=20-24$. For this type of oils, and also based on the isoabundance plot for the sample (Figure S8), $\mathrm{O}_{4}$ species can be assigned to sinapyl alcohol $(\mathrm{DBE}=5, \# \mathrm{C}=11)$ type species derived from the syringyl lignin units. The main concentration of clusters for $\mathrm{O}_{4}$ and $\mathrm{O}_{5}$ species is detected in the region with carbon number 13-23 and DBE $=7-9$ (Figure S8d-e), indicating that the remaining non-depolymerized ligninderived structures possess unsaturated chains attached, as well as additional oxygenated functional groups (i.e. $-\mathrm{OH}$ or $-\mathrm{OCH}_{3}$ groups). In addition, high concentrations along $\mathrm{DBE}=4$ and carbon number range 22-27 are also detected, pointing out the presence of analogue sinapyl alcoholderived structures with long saturated alkyl chains. 

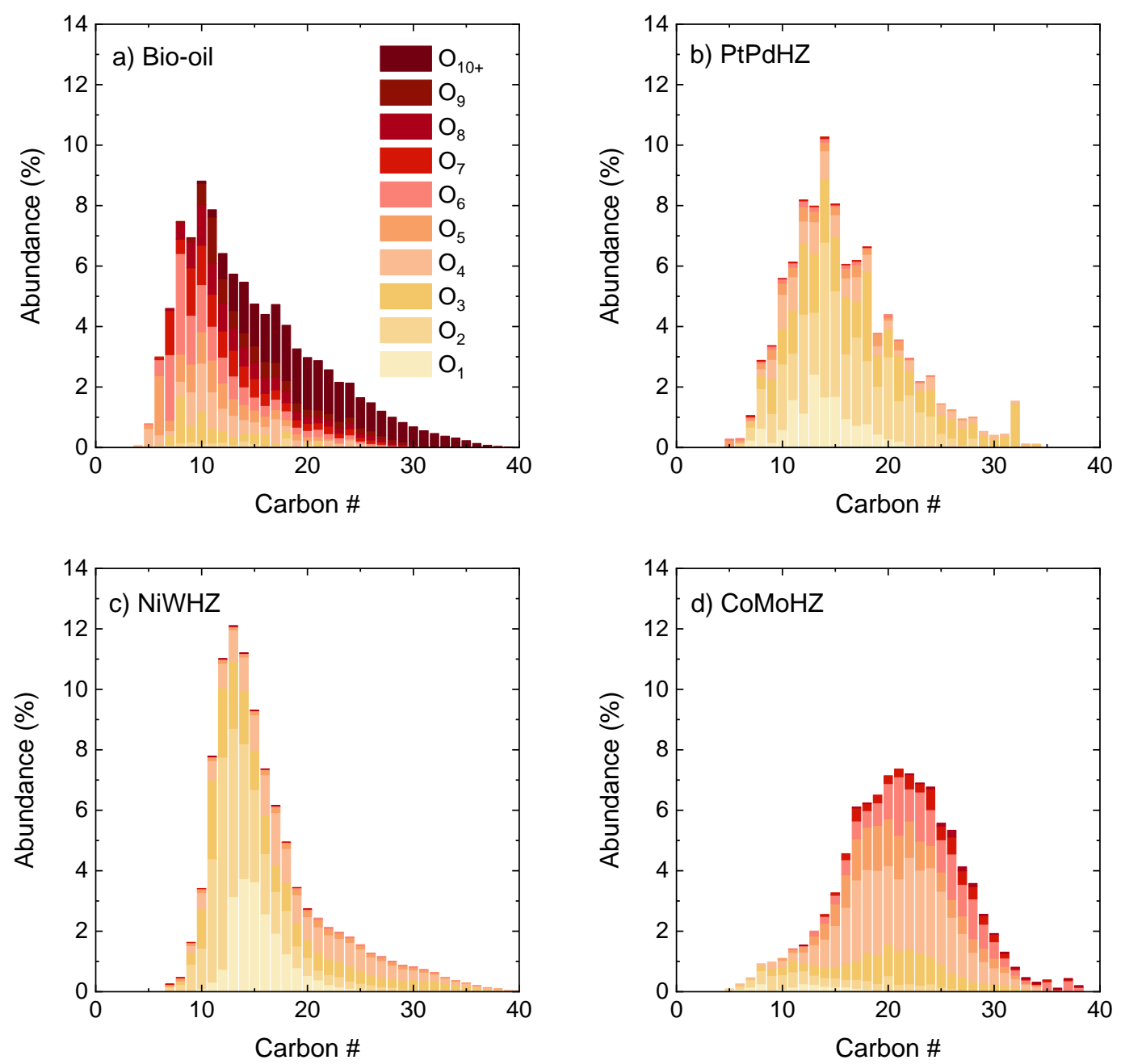

Figure 5. Distribution of the oxygenated compounds on a carbon number basis in the a) raw biooil feedstock and b-d) the organic product fractions obtained using the different catalysts as measured from (-)ESI FT-ICR/MS

\section{Aromatics}

The complex reaction network involved in the HDO conversion also comprises double bond hydrogenations, cracking reactions, dealkylation, and/or demethanation reactions, among others, which will also transform the oxygen-free hydrocarbons $(\mathrm{HC})$ in the products. Figure 6 displays the color-coded isoabundance plots for these species as analyzed through (+)APPI FT-ICR/MS. Since radical species account for $>65 \%$ of the HCs of the analyzed samples, we have only 
considered these species for the isoabundance plot as representative of the HCs. The small fraction of $\mathrm{HC}$ detected on the organic bio-oil fraction (4.5\%, Figure 6a) reveals a heterogeneous distribution of compounds with DBE $<10$. Conversely, the significantly higher amount of HC measured for the PtPdHZ sample (Figure 6b) presents a well-defined high-concentration cluster consisting of species with 10-16 carbon atoms and DBE in the 5-10 range. These compounds can be assigned to 1-ring or 2-ring aromatic structures with short unsaturated chains attached, in line with the results in Figure 2b, where aromatics up to anthracene-type molecules could be detected. In the case of the NiWHZ catalyst (Figure 6c), hydrocarbon compounds are bulkier, with 18-28 carbon atoms and a higher saturation degree $(\mathrm{DBE}=10-20 . \mathrm{HC}$ compounds for this organic product fraction predominantly consist of $3^{+}$aromatic rings, like anthracene $(C \#=14, \mathrm{DBE}=10)$, pyrene $(C \#=16, \mathrm{DBE}=12)$, benzoanthracene $(\mathrm{C} \#=18, \mathrm{DBE}=13)$, benzofluoranthene $(\mathrm{C} \#=20$, $\mathrm{DBE}=12)$, benzopyrene $(\mathrm{C} \#=20, \mathrm{DBE}=15)$, and analogue heavily condensed species. Lastly, the CoMoHZ catalyst (Figure 6d) reveals HC compounds with a somewhat similar nature to those detected for the NiWHZ catalyst, presenting high concentrations in the DBE $=5-15$ region and $\mathrm{C \#}$ $=10-25$. 


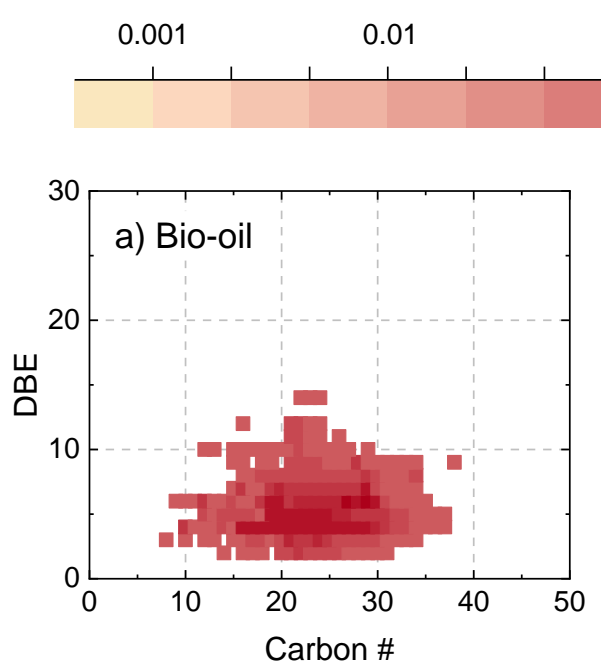

$\begin{array}{ll}0.1 & 1.0\end{array}$
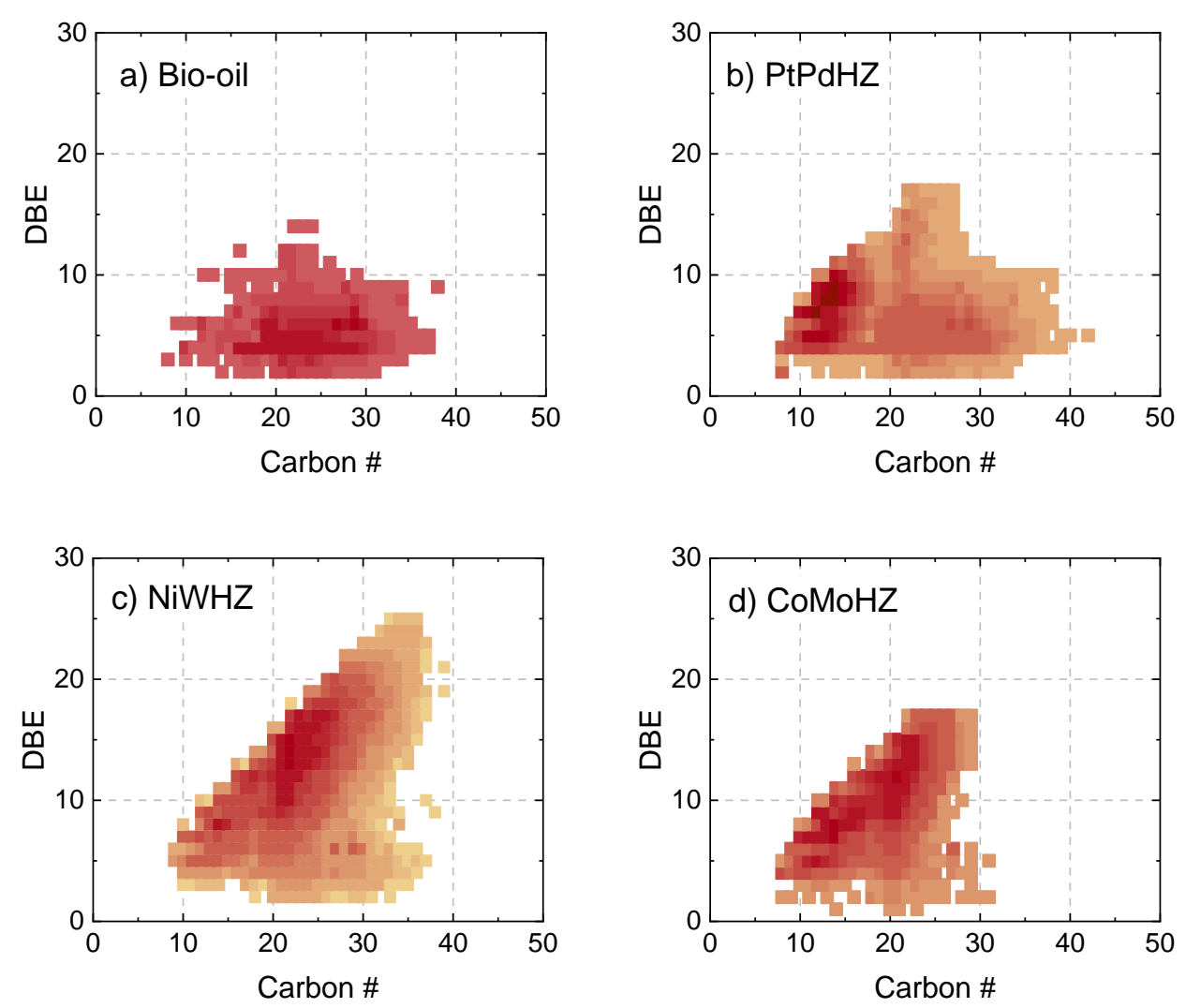

Figure 6. Color-coded isoabundance plots of DBE versus carbon number for the hydrocarbons (HCs) of the a) raw bio-oil and b-d) organic product oils as measured through (+)APPI FTICR/MS.

\section{Discussion}

One criterion for comparing the performance of the used catalyst is by defining cumulative HDO and hydrotreatment/hydrocracking (HT/HC) conversions, as defined by Eq. 4 and Eq. 5, respectively. The distribution of the cumulative HDO conversion of the oxygenates in bio-oil on the basis of their oxygen number is plotted in Figure 7a. The results of both PtPdHZ and NiWHZ catalysts are comparable, converting $>51 \%$ of the total $\mathrm{O}_{3+}$ species originally present in the raw bio-oil feedstock, while the lower activity of the CoMoHZ catalyst only converts a $6.1 \%$ of the same fraction. Overall, the activity of the CoMoHZ catalyst is about $80-90 \%$ lower in contrast to 
the other two catalysts for the conversion of the lighter $\mathrm{O}_{2+-} \mathrm{O}_{4+}$ fraction. With all three catalysts, a $100 \%$ conversion of the $\mathrm{O}_{9+}$ fraction in the raw bio-oil (34.7\% of its total composition) is attained. On the other hand, Figure 7b displays the evolution of the HT/HC conversion of the HCclass species as measured by (+)APPI. The $\mathrm{C}_{16+}$ fraction originally present in bio-oil is efficiently converted by the PtPdHZ catalyst in ca. $67 \%$, while these values remain significantly lower for the CoMoHZ (26\%) and NiWHZ (5\%) catalysts. Despite their very similar HDO performance, while the NiWHZ catalyst has a higher activity for the removal of oxygen, CoMoHZ is more active for removing polycondensed aromatics through hydrogenation, cracking and ring opening reactions. ${ }^{39}$
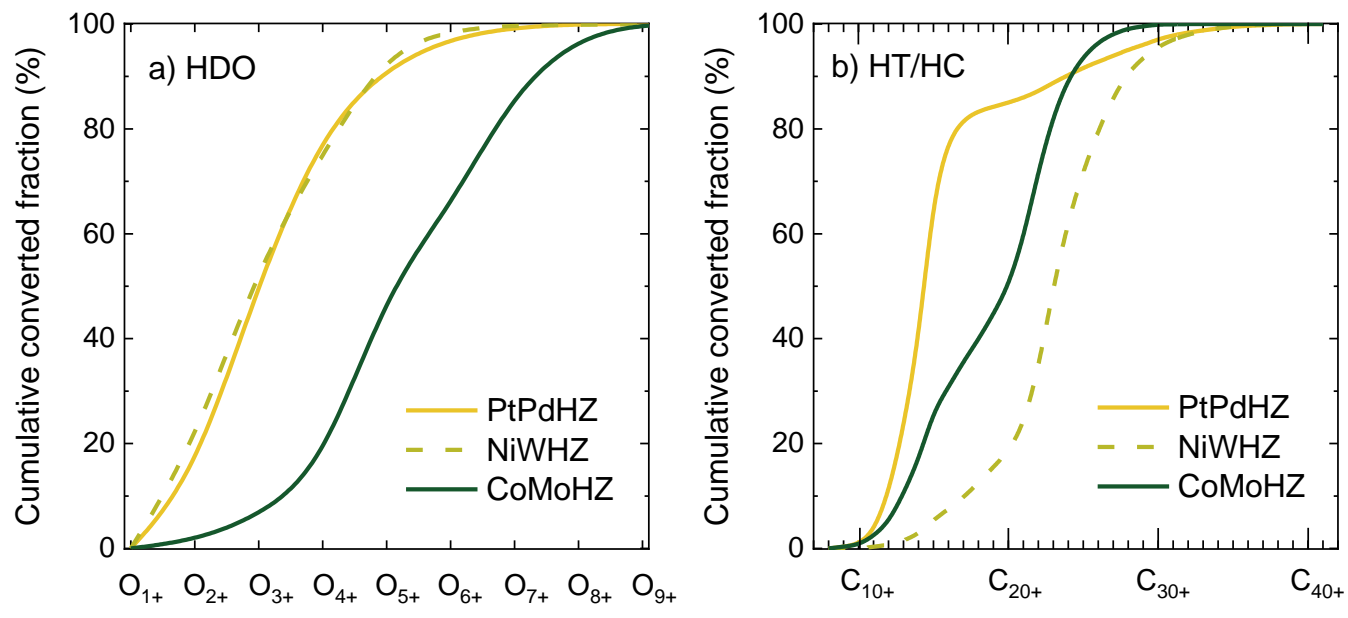

Figure 7. Evolution of the cumulative a) HDO and b) HT/HC conversion of the raw bio-oil using the different catalysts.

An overview of the chemical nature of the predominant species in the oxygenates and hydrocarbon lumps formed with the different catalysts is provided in Scheme 2. The PtPdHZ catalyst was the overall most active on both the HDO and HT/HC routes (Figure 7), providing the lightest oxygenated and hydrocarbons, yielding heavily deoxygenated organic products with a significant content of aromatics in both the volatile and non GC-detectable fractions (see Figure $3 \mathrm{~b}$ and Figure 5). However, this catalyst also greatly promotes the formation of gas products and heavily condensed coke (Figure 1a and Figure 1c). On the other hand, and despite providing almost 
identical HDO conversion (Figure 8a), the nature of the oxygenated compounds in the NiWHZ catalyst was slightly heavier. The aromatics formed using the NiWHZ catalyst are clearly bulkier (Figure 6c), as a consequence of its lower activity towards HT/HC reactions (Figure 7b), leading to the formation of molecules of up to 25-30 carbon atoms. Lastly, the CoMoHZ catalyst yields a heavier organic product, mainly due to the higher molecular weight of the oxygenates present in it (Figure 5d). Comparatively, its HDO activity is much lower (Figure 7a), which might render the product oil unstable and still not sufficiently upgraded. All in all, a mildly active NiWHZ catalyst combination is the most suitable for the production of interesting aromatic and phenolic monomers, also providing a good compromise between the main product yields, maximizing liquid products with the lowest gas and coke formation.

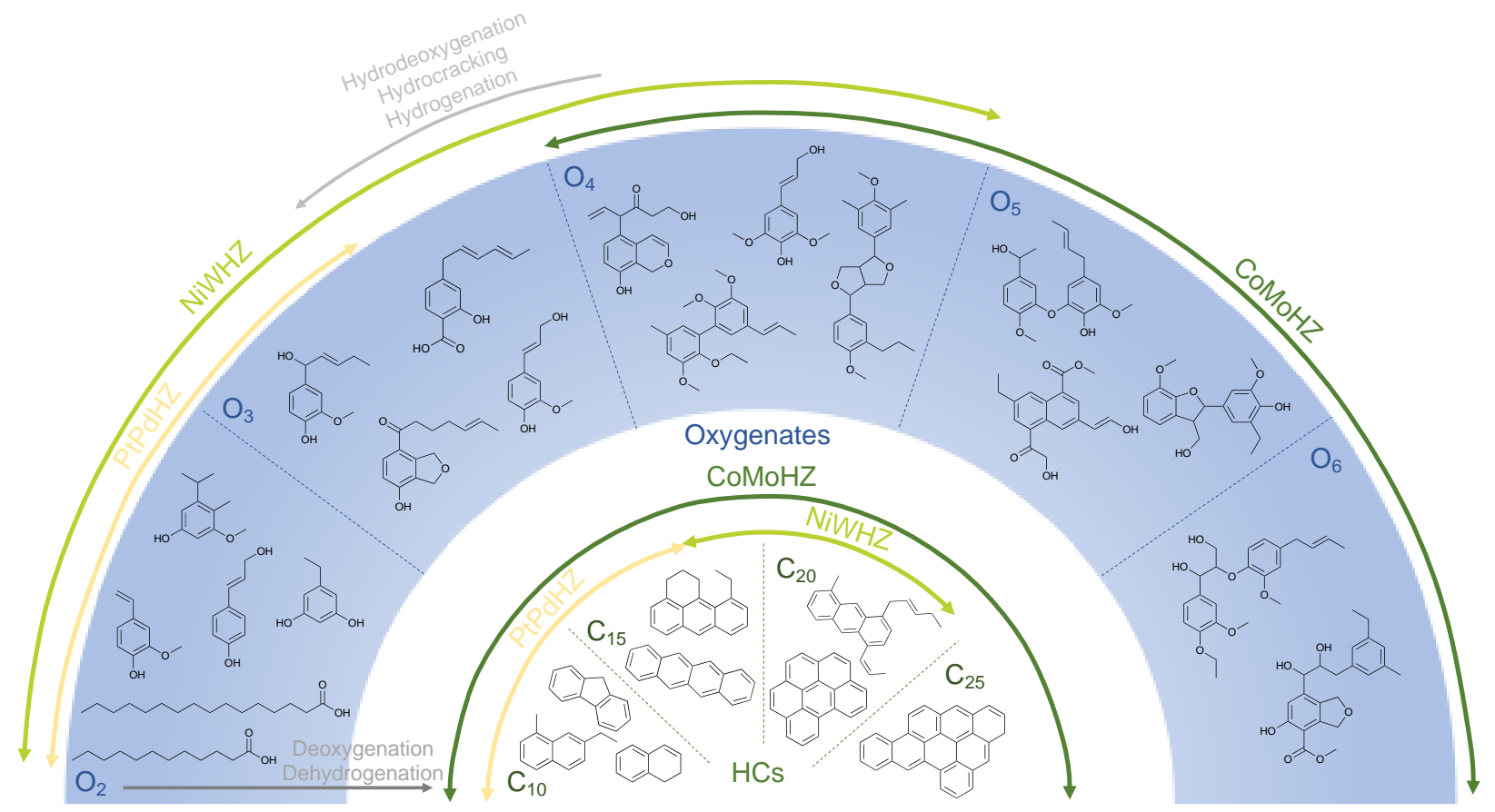

Scheme 2. Overview of the main range of aromatic and oxygenated products preferentially formed in the non-volatile fraction of the organic products produced in the HDO of a raw bio-oil using either PtPdHZ, NiWHZ or CoMoHZ catalysts.

All in all, our study has showcased a multi-technique approach that allows for the complete characterization of the reaction media during the HDO of raw bio-oil. While gas chromatgroaphy techniques are optimal for the analysis of either the gas products and the aqueous product phase, 
these techniques are insufficient for completely analyzing the organic product fraction. The limitations of GC columns and ovens causes a significant fraction of these liquids to not be analyzed, hence remaining overlooked in studies which aim at an insightful understanding of the reaction routes and kinetics. For a realistic and complete compositional overview, complementary FT-ICR/MS must be incorporated, presenting a much more advanced detection and predictive capacity, and with the potential of covering the existing analytical gap for the heaviest organic fraction. The whole molecular weight range of the compounds in bio-oil and organic products can most accurately be estimated through GPC techniques, which, combined with GC, allow for estimating the volatiles (GC-detectable) fractions of the analyzed liquids. Coke quantification can be conducted through TG analysis and, due to the existence of clearly distinguishable coke types, it is also possible to have an estimation on the condensation degree of the formed coke. The acquisition of further structural information would required of more advanced techniques like LDI FT-ICR/MS or ${ }^{13} \mathrm{C}$ CP/MAS NMR. All the collected data through our proposed multi-technique approach allows for the prediction of model representative molecules of each fraction, which can more realistically represent each product fraction in kinetic models and simulations, aiming for improved reaction, reactor and catalyst design.

\section{Conclusions}

In this work we propose an analytical procedure for following the raw bio-oil hydrodeoxygenation, through the intensive characterization of the raw bio-oil and its HDO products. We have applied this methodology for fully describing the conversion and composition of the heaviest bio-oil and HDO organic products, in order to be able to establish a diagram with the formed preferential products on a basis of their carbon and oxygen number.

The methodology requires an efficient separation of all the product fractions in the first place: gas, liquids (organic and aqueous fraction) and solid (coke), and then use specific techniques for each fraction. We have proved by GPC, that a great proportion of the organic fraction can remain undetected through traditional GC techniques. This heavier fraction of the bio-oil reactant or product has been analyzed in detail using FT-ICR/MS with a combination of (-)ESI and (+)APPI ionization methods. Specifically, we have tracked the evolution of heavy oxygenates and aromatics present in the organic liquid product fraction in order to gather valuable structural and compositional information on the main compounds present in said fractions, also the most 
refractory and heavy to convert. The assessment of the cumulative conversions of oxygenates and carbon distribution lead to more reliable and systematic way to compare catalyst activity. Our work illustrates the key role of heavy species (oxygenates and aromatics in this case) in the HDO of biooil. Considering the reactivity of these compounds and the assessment of the cumulative conversion of oxygenates and hydrocarbons in bio-oil led to a more reliable way to compare catalyst activity.

\section{Acknowledgements}

This work was carried out with the support of the Ministry of Economy and Competitiveness of the Spanish Government, some co-founded with ERDF funds (CTQ2015-67425-R, CTQ201568654-R, and CTQ2016-79646-P), the Basque Government (IT1218-19) and the European Commission (Horizon H2020-MSCA RISE-2018, Contract No. 823745). This work was also supported by the European Union Horizon 2020 Research and Innovation Programme (Grant No. 731077), the Academy of Finland (Grant No. 259901) and the Strategic Research Council (Grant No. 293380). The FT-ICR MS facility was supported by Biocenter Finland, Biocenter Kuopio and the European Regional Development Fund (Grant No. A70135).

\section{Supporting Information}

Supporting Information is available free of charge at https://pubs.acs.org/doi/XXX.

Figure S1. Isoabundance plot for the oxygenated species of bio-oil, Figure S2. DTG-TPO of deactivated catalysts, Table S1. detailed chemical composition of the organic products, Figure S3. total detected species through FT-ICR/MS using the different ionization methods in bio-oil and the organic products, Figure S4. carbon number distributions of the organic products as calculated from the $\mathrm{GC} \times \mathrm{GC} / \mathrm{MS}$ data, Figures S5-S8. color-coded isoabundance plots of DBE versus carbon number classified per oxygen number for the oxygenated species in raw bio-oil and the organic products fractions.

\section{Conflict of Interest}

The authors declare no conflicts of interest

\section{References}

(1) Corma Canos, A.; Iborra, S.; Velty, A. Chemical Routes for the Transformation of Biomass into Chemicals. Chem. Rev. 2007, 107 (6), 2411-2502. DOI 10.1021/cr050989d. 
(2) Bajwa, D. S.; Peterson, T.; Sharma, N.; Shojaeiarani, J.; Bajwa, S. G. A Review of Densified Solid Biomass for Energy Production. Renew. Sustain. Energy Rev. 2018, 96, 296-305. DOI 10.1016/j.rser.2018.07.040.

(3) Panwar, N. L.; Kothari, R.; Tyagi, V. V. Thermo Chemical Conversion of Biomass - Eco Friendly Energy Routes. Renew. Sustain. Energy Rev. 2012, 16 (4), 1801-1816. DOI 10.1016/j.rser.2012.01.024.

(4) El-Dalatony, M. M.; Salama, E.-S.; Kurade, M. B.; Kim, K.-Y.; Govindwar, S. P.; Kim, J. R.; Kwon, E. E.; Min, B.; Jang, M.; Oh, S.-E.; et al. Whole Conversion of Microalgal Biomass into Biofuels through Successive High-Throughput Fermentation. Chem. Eng. J. 2019, 360, 797-805. DOI 10.1016/j.cej.2018.12.042.

(5) Kumar, R.; Strezov, V.; Weldekidan, H.; He, J.; Singh, S.; Kan, T.; Dastjerdi, B. Lignocellulose Biomass Pyrolysis for Bio-Oil Production: A Review of Biomass PreTreatment Methods for Production of Drop-in Fuels. Renew. Sustain. Energy Rev. 2020, 123, 109763. DOI 10.1016/j.rser.2020.109763.

(6) Bridgwater, A. V. Review of Fast Pyrolysis of Biomass and Product Upgrading. Biomass Bioenergy 2012, 38, 68-94. DOI 10.1016/j.biombioe.2011.01.048.

(7) Palizdar, A.; Sadrameli, S. M. Catalytic Upgrading of Biomass Pyrolysis Oil over Tailored Hierarchical MFI Zeolite: Effect of Porosity Enhancement and Porosity-Acidity Interaction on Deoxygenation Reactions. Renew. Energy 2020, 148, 674-688. DOI 10.1016/j.renene.2019.10.155.

(8) Ibarra, Á.; Hita, I.; Arandes, J. M.; Bilbao, J. Influence of the Composition of Raw BioOils on Their Valorization in Fluid Catalytic Cracking Conditions. Energy Fuels 2019, 33 (8), 7458-7465. DOI 10.1021/acs.energyfuels.9b01527.

(9) Figueirêdo, M. B.; Deuss, P. J.; Venderbosch, R. H.; Heeres, H. J. Valorization of Pyrolysis Liquids: Ozonation of the Pyrolytic Lignin Fraction and Model Components. ACS Sustain. Chem. Eng. 2019, 7 (5), 4755-4765. DOI 10.1021/acssuschemeng.8b04856.

(10) Lazzari, E.; Schena, T.; Marcelo, M. C. A.; Primaz, C. T.; Silva, A. N.; Ferrão, M. F.; Bjerk, T.; Caramão, E. B. Classification of Biomass through Their Pyrolytic Bio-Oil Composition Using FTIR and PCA Analysis. Ind. Crops Prod. 2018, 111, 856-864. DOI 10.1016/j.indcrop.2017.11.005.

(11) Gollakota, A. R. K.; Reddy, M.; Subramanyam, M. D.; Kishore, N. A Review on the Upgradation Techniques of Pyrolysis Oil. Renew. Sustain. Energy Rev. 2016, 58, 15431568. DOI 10.1016/j.rser.2015.12.180.

(12) Czernik, S.; Bridgwater, A. V. Overview of Applications of Biomass Fast Pyrolysis Oil. Energy Fuels 2004, 18 (2), 590-598. DOI 10.1021/ef034067u.

(13) Harman-Ware, A. E.; Ferrell, J. R. Methods and Challenges in the Determination of Molecular Weight Metrics of Bio-Oils. Energy Fuels 2018, 32 (9), 8905-8920. DOI 10.1021/acs.energyfuels.8b02113.

(14) Jiang, S.-F.; Sheng, G.-P.; Jiang, H. Advances in the Characterization Methods of Biomass Pyrolysis Products. ACS Sustain. Chem. Eng. 2019, 7 (15), 12639-12655. DOI 10.1021/acssuschemeng.9b00868.

(15) Wang, Y.; Han, Y.; Hu, W.; Fu, D.; Wang, G. Analytical Strategies for Chemical Characterization of Bio-Oil. J. Sep. Sci. 2020, 43 (1), 360-371. DOI 10.1002/jssc.201901014.

(16) Ware, R. L.; Rowland, S. M.; Rodgers, R. P.; Marshall, A. G. Advanced Chemical Characterization of Pyrolysis Oils from Landfill Waste, Recycled Plastics, and Forestry 
Residue. Energy Fuels 2017, 31 (8), 8210-8216. DOI 10.1021/acs.energyfuels.7b00865.

(17) Staš, M.; Auersvald, M.; Kejla, L.; Vrtiška, D.; Kroufek, J.; Kubička, D. Quantitative Analysis of Pyrolysis Bio-Oils: A Review. TrAC Trends Anal. Chem. 2020, 126, 115857. DOI 10.1016/j.trac.2020.115857.

(18) Kekäläinen, T.; Pakarinen, J. M. H.; Wickström, K.; Lobodin, V. V; McKenna, A. M.; Jänis, J. Compositional Analysis of Oil Residues by Ultrahigh-Resolution Fourier Transform Ion Cyclotron Resonance Mass Spectrometry. Energy Fuels 2013, 27 (4), 2002-2009. DOI 10.1021/ef301762v.

(19) Smith, D. F.; Podgorski, D. C.; Rodgers, R. P.; Blakney, G. T.; Hendrickson, C. L. 21 Tesla FT-ICR Mass Spectrometer for Ultrahigh-Resolution Analysis of Complex Organic Mixtures. Anal. Chem. 2018, 90 (3), 2041-2047. DOI 10.1021/acs.analchem.7b04159.

(20) Miettinen, I.; Kuittinen, S.; Paasikallio, V.; Mäkinen, M.; Pappinen, A.; Jänis, J. Characterization of Fast Pyrolysis Oil from Short-Rotation Willow by High-Resolution Fourier Transform Ion Cyclotron Resonance Mass Spectrometry. Fuel 2017, 207, 189197. DOI 10.1016/j.fuel.2017.06.053.

(21) Palos, R.; Kekäläinen, T.; Duodu, F.; Gutiérrez, A.; Arandes, J. M.; Jänis, J.; Castaño, P. Screening Hydrotreating Catalysts for the Valorization of a Light Cycle Oil/Scrap Tires Oil Blend Based on a Detailed Product Analysis. Appl. Catal. B Environ. 2019, 256, 117863. DOI 10.1016/j.apcatb.2019.117863.

(22) Al Jamri, M.; Li, J.; Smith, R. Molecular Characterisation of Biomass Pyrolysis Oil and Petroleum Fraction Blends. Comput. Chem. Eng. 2020, 140, 106906. DOI 10.1016/j.compchemeng.2020.106906.

(23) Wang, N.; Zhi, Y.; Wei, Y.; Zhang, W.; Liu, Z.; Huang, J.; Sun, T.; Xu, S.; Lin, S.; He, Y.; et al. Molecular Elucidating of an Unusual Growth Mechanism for Polycyclic Aromatic Hydrocarbons in Confined Space. Nat. Commun. 2020, 11 (1), 1079-1091. DOI 10.1038/s41467-020-14493-9.

(24) Palacio Lozano, D. C.; Ramírez, C. X.; Sarmiento Chaparro, J. A.; Thomas, M. J.; Gavard, R.; Jones, H. E.; Cabanzo Hernández, R.; Mejia-Ospino, E.; Barrow, M. P. Characterization of Bio-Crude Components Derived from Pyrolysis of Soft Wood and Its Esterified Product by Ultrahigh Resolution Mass Spectrometry and Spectroscopic Techniques. Fuel 2020, 259, 116085. DOI 10.1016/j.fuel.2019.116085.

(25) Ware, R. L.; Rodgers, R. P.; Marshall, A. G.; Mante, O. D.; Dayton, D. C.; Verdier, S.; Gabrielsen, J.; Rowland, S. M. Detailed Chemical Composition of an Oak Biocrude and Its Hydrotreated Product Determined by Positive Atmospheric Pressure Photoionization Fourier Transform Ion Cyclotron Resonance Mass Spectrometry. Sustain. Energy Fuels 2020, 4 (5), 2404-2410. DOI 10.1039/C9SE00837C.

(26) Michailof, C. M.; Kalogiannis, K. G.; Sfetsas, T.; Patiaka, D. T.; Lappas, A. A. Advanced Analytical Techniques for Bio-Oil Characterization. Wiley Interdiscip. Rev. Energy Environ. 2016, 5 (6), 614-639. DOI 10.1002/wene.208.

(27) Usman, M.; Chen, H.; Chen, K.; Ren, S.; Clark, J. H.; Fan, J.; Luo, G.; Zhang, S. Characterization and Utilization of Aqueous Products from Hydrothermal Conversion of Biomass for Bio-Oil and Hydro-Char Production: A Review. Green Chem. 2019, 21 (7), 1553-1572. DOI 10.1039/C8GC03957G.

(28) Jin, W.; Pastor-Pérez, L.; Yu, J.; Odriozola, J. A.; Gu, S.; Reina, T. R. Cost-Effective Routes for Catalytic Biomass Upgrading. Curr. Opin. Green Sustain. Chem. 2020, 23, 19. DOI 10.1016/j.cogsc.2019.12.008. 
(29) Cordero-Lanzac, T.; Palos, R.; Arandes, J. M.; Castaño, P.; Rodríguez-Mirasol, J.;

Cordero, T.; Bilbao, J. Stability of an Acid Activated Carbon Based Bifunctional Catalyst for the Raw Bio-Oil Hydrodeoxygenation. Appl. Catal. B Environ. 2017, 203, 389-399. DOI 10.1016/j.apcatb.2016.10.018.

(30) Zacher, A. H.; Elliott, D. C.; Olarte, M. V; Wang, H.; Jones, S. B.; Meyer, P. A. Technology Advancements in Hydroprocessing of Bio-Oils. Biomass Bioenergy 2019, 125, 151-168. DOI 10.1016/j.biombioe.2019.04.015.

(31) Kim, S.; Kwon, E. E.; Kim, Y. T.; Jung, S.; Kim, H. J.; Huber, G. W.; Lee, J. Recent Advances in Hydrodeoxygenation of Biomass-Derived Oxygenates over Heterogeneous Catalysts. Green Chem. 2019, 21 (14), 3715-3743. DOI 10.1039/c9gc01210a.

(32) Zacher, A. H.; Olarte, M. V.; Santosa, D. M.; Elliott, D. C.; Jones, S. B. A Review and Perspective of Recent Bio-Oil Hydrotreating Research. Green Chem. 2014, 16 (2), 491515. DOI 10.1039/c3gc41382a.

(33) Fan, X.; Wu, Y.; Li, Z.; Sun, Y.; Tu, R.; Zhong, P.-D.; Jiang, E.; Xu, X. Benzene, Toluene and Xylene (BTX) from in-Situ Gas Phase Hydrodeoxygenation of Guaiacol with Liquid Hydrogen Donor over Bifunctional Non-Noble-Metal Zeolite Catalysts. Renew. Energy 2020, 152, 1391-1402. DOI 10.1016/j.renene.2020.01.015.

(34) Santos, J. L.; Mäki-Arvela, P.; Wärnå, J.; Monzón, A.; Centeno, M. A.; Murzin, D. Y. Hydrodeoxygenation of Vanillin over Noble Metal Catalyst Supported on Biochars: Part II: Catalytic Behaviour. Appl. Catal. B Environ. 2020, 268, 118425. DOI 10.1016/j.apcatb.2019.118425.

(35) Ju, C.; Li, M.; Fang, Y.; Tan, T. Efficient Hydro-Deoxygenation of Lignin Derived Phenolic Compounds over Bifunctional Catalysts with Optimized Acid/Metal Interactions. Green Chem. 2018, 20 (19), 4492-4499. DOI 10.1039/c8gc01960f.

(36) Yang, S.; Luo, K.; Fang, M.; Zhang, K.; Fan, J. Parallel CFD-DEM Modeling of the Hydrodynamics in a Lab-Scale Double Slot-Rectangular Spouted Bed with a Partition Plate. Chem. Eng. J. 2014, 236 (0), 158-170. DOI 10.1016/j.cej.2013.09.082.

(37) Hita, I.; Cordero-Lanzac, T.; García-Mateos, F. J.; Azkoiti, M. J.; Rodríguez-Mirasol, J.; Cordero, T.; Bilbao, J. Enhanced Production of Phenolics and Aromatics from Raw BioOil Using HZSM-5 Zeolite Additives for PtPd/C and NiW/C Catalysts. Appl. Catal. B Environ. 2019, 118112. DOI 10.1016/j.apcatb.2019.118112.

(38) Cordero-Lanzac, T.; Palos, R.; Hita, I.; Arandes, J. M.; Rodríguez-Mirasol, J.; Cordero, T.; Bilbao, J.; Castaño, P. Revealing the Pathways of Catalyst Deactivation by Coke during the Hydrodeoxygenation of Raw Bio-Oil. Appl. Catal. B Environ. 2018, 239, 513 524. DOI 10.1016/j.apcatb.2018.07.073.

(39) Cordero-Lanzac, T.; Hita, I.; García-Mateos, F. J.; Castaño, P.; Rodríguez-Mirasol, J.; Cordero, T.; Bilbao, J. Adaptable Kinetic Model for the Transient and Pseudo-Steady States in the Hydrodeoxygenation of Raw Bio-Oil. Chem. Eng. J. 2020, 124679. DOI 10.1016/j.cej.2020.124679.

(40) Hita, I.; Gutiérrez, A.; Olazar, M.; Bilbao, J.; Arandes, J. M.; Castaño, P. Upgrading Model Compounds and Scrap Tires Pyrolysis Oil (STPO) on Hydrotreating NiMo Catalysts with Tailored Supports. Fuel 2015, 145, 158-169. DOI 10.1016/j.fuel.2014.12.055.

(41) van Herk, D.; Castaño, P.; Quaglia, M.; Kreutzer, M. T.; Makkee, M.; Moulijn, J. A. Avoiding Segregation during the Loading of a Catalyst-Inert Powder Mixture in a Packed Micro-Bed. Appl. Catal. A Gen. 2009, 365 (1), 110-121. DOI 
10.1016/j.apcata.2009.06.003.

(42) Fernandez-Akarregi, A. R.; Makibar, J.; Lopez, G.; Amutio, M.; Olazar, M. Design and Operation of a Conical Spouted Bed Reactor Pilot Plant $(25 \mathrm{Kg} / \mathrm{h})$ for Biomass Fast Pyrolysis. Fuel Process. Technol. 2013, 112, 48-56. DOI 10.1016/j.fuproc.2013.02.022.

(43) Yin, W.; Tang, Z.; Venderbosch, R. H.; Zhang, Z.; Cannilla, C.; Bonura, G.; Frusteri, F.; Heeres, H. J. A One-Step Synthesis of C6 Sugar Alcohols from Levoglucosan and Disaccharides Using a Ru/CMK-3 Catalyst. ACS Catal. 2016, 6 (7), 4411-4422. DOI 10.1021/acscatal.6b00296.

(44) Sedai, B.; Zhou, J. L.; Fakhri, N.; Sayari, A.; Baker, R. T. Solid Phase Extraction of BioOil Model Compounds and Lignin-Derived Bio-Oil Using Amine-Functionalized Mesoporous Silicas. ACS Sustain. Chem. Eng. 2018, 6 (8), 9716-9724. DOI 10.1021/acssuschemeng.8b00747.

(45) Lu, K.; Hao, N.; Meng, X.; Luo, Z.; Tuskan, G. A.; Ragauskas, A. J. Investigating the Correlation of Biomass Recalcitrance with Pyrolysis Oil Using Poplar as the Feedstock. Bioresour. Technol. 2019, 289, 121589. DOI 10.1016/j.biortech.2019.121589.

(46) Mullen, C. A.; Boateng, A. A. Mild Hydrotreating of Bio-Oils with Varying Oxygen Content Produced via Catalytic Fast Pyrolysis. Fuel 2019, 245, 360-367. DOI 10.1016/J.FUEL.2019.02.027.

(47) Kekäläinen, T.; Pakarinen, J. M. H.; Wickström, K.; Vainiotalo, P. Compositional Study of Polar Species in Untreated and Hydrotreated Gas Oil Samples by Electrospray Ionization Fourier Transform Ion Cyclotron Resonance Mass Spectrometry (ESI FTICR MS). Energy Fuels 2009, 23 (12), 6055-6061. DOI 10.1021/ef9007592.

(48) Zhang, J.; Chen, T.; Jiao, Y.; Wang, L.; Wang, J.; Chen, Y.; Zhu, Q.; Li, X. Role of Acidity in Catalytic Cracking of N-Decane over Supported Pt-Based Catalysts. Appl. Surf. Sci. 2020, 507, 145113. DOI 10.1016/j.apsusc.2019.145113.

(49) Ardiyanti, A. R.; Gutierrez, A.; Honkela, M. L.; Krause, A. O. I.; Heeres, H. J. Hydrotreatment of Wood-Based Pyrolysis Oil Using Zirconia-Supported Mono- and Bimetallic (Pt, Pd, Rh) Catalysts. Appl. Catal. A Gen. 2011, 407 (1-2), 56-66. DOI 10.1016/j.apcata.2011.08.024.

(50) Ardiyanti, A. R.; Bykova, M. V; Khromova, S. A.; Yin, W.; Venderbosch, R. H.; Yakovlev, V. A.; Heeres, H. J. Ni-Based Catalysts for the Hydrotreatment of Fast Pyrolysis Oil. Energy Fuels 2016, 30 (3), 1544-1554. DOI 10.1021/acs.energyfuels.5b02223.

(51) Figueirêdo, M. B.; Jotic, Z.; Deuss, P. J.; Venderbosch, R. H.; Heeres, H. J. Hydrotreatment of Pyrolytic Lignins to Aromatics and Phenolics Using Heterogeneous Catalysts. Fuel Process. Technol. 2019, 189, 28-38. DOI 10.1016/j.fuproc.2019.02.020.

(52) Perera, D. C.; Hewage, J. W.; De Silva, N. Theoretical Study of Catalytic Decomposition of Acetic Acid on MgO Nanosurface. 2015, 1064, 1-6. DOI 10.1016/j.comptc.2015.04.011.

(53) Hita, I.; Cordero-Lanzac, T.; Bonura, G.; Frusteri, F.; Bilbao, J.; Castaño, P. Dynamics of Carbon Formation during the Catalytic Hydrodeoxygenation of Raw Bio-Oil. Sustain. Energy Fuels 2020, 4, 5503-5512. DOI 10.1039/D0SE00501K.

(54) Hita, I.; Cordero-Lanzac, T.; Bonura, G.; Cannilla, C.; Arandes, J. M.; Frusteri, F.; Bilbao, J. Hydrodeoxygenation of Raw Bio-Oil towards Platform Chemicals over FeMoP/Zeolite Catalysts. J. Ind. Eng. Chem. 2019, 80, 392-400. DOI 10.1016/j.jiec.2019.08.019. Benés, M.; Bilbao, R.; Santos, J. M.; Alves Melo, J.; Wisniewski, A.; Fonts, I. 
Hydrodeoxygenation of Lignocellulosic Fast Pyrolysis Bio-Oil: Characterization of the Products and Effect of the Catalyst Loading Ratio. Energy Fuels 2019, 33 (5), 4272-4286. DOI 10.1021/acs.energyfuels.9b00265.

(56) Figueirêdo, M. B.; Deuss, P. J.; Venderbosch, R. H.; Heeres, H. J. Catalytic Hydrotreatment of Pyrolytic Lignins from Different Sources to Biobased Chemicals: Identification of Feed-Product Relations. Biomass Bioenergy 2020, 134, 105484. DOI 10.1016/j.biombioe.2020.105484.

(57) Kekäläinen, T.; Venäläinen, T.; Jänis, J. Characterization of Birch Wood Pyrolysis Oils by Ultrahigh-Resolution Fourier Transform Ion Cyclotron Resonance Mass Spectrometry: Insights into Thermochemical Conversion. Energy Fuels 2014, 28 (7), 4596-4602. DOI 10.1021/ef500849z.

(58) Soares, J. F.; Zabot, G. L.; Tres, M. V; Lunelli, F. C.; Rodrigues, V. M.; Friedrich, M. T.; Pazinatto, C. A.; Bilibio, D.; Mazutti, M. A.; Carniel, N.; et al. Supercritical CO2 Extraction of Black Poplar (Populus Nigra L.) Extract: Experimental Data and Fitting of Kinetic Parameters. J. Supercrit. Fluids 2016, 117, 270-278. DOI 10.1016/j.supflu.2016.07.005.

(59) Peng, W.; Li, D.; Zhang, M.; Ge, S.; Mo, B.; Li, S.; Ohkoshi, M. Characteristics of Antibacterial Molecular Activities in Poplar Wood Extractives. Saudi J. Biol. Sci. 2017, 24 (2), 399-404. DOI 10.1016/j.sjbs.2015.10.026.

(60) Hita, I.; Heeres, H. J.; Deuss, P. J. Insight into Structure-Reactivity Relationships for the Iron-Catalyzed Hydrotreatment of Technical Lignins. Bioresour. Technol. 2018, 267, 93101. DOI 10.1016/J.BIORTECH.2018.07.028. 


\section{For Table of Contents Use Only}

A multi-technique analytical approach is paramount for a well-founded catalyst performance assessment in the upgrading of raw bio-oil towards valuable platform chemicals

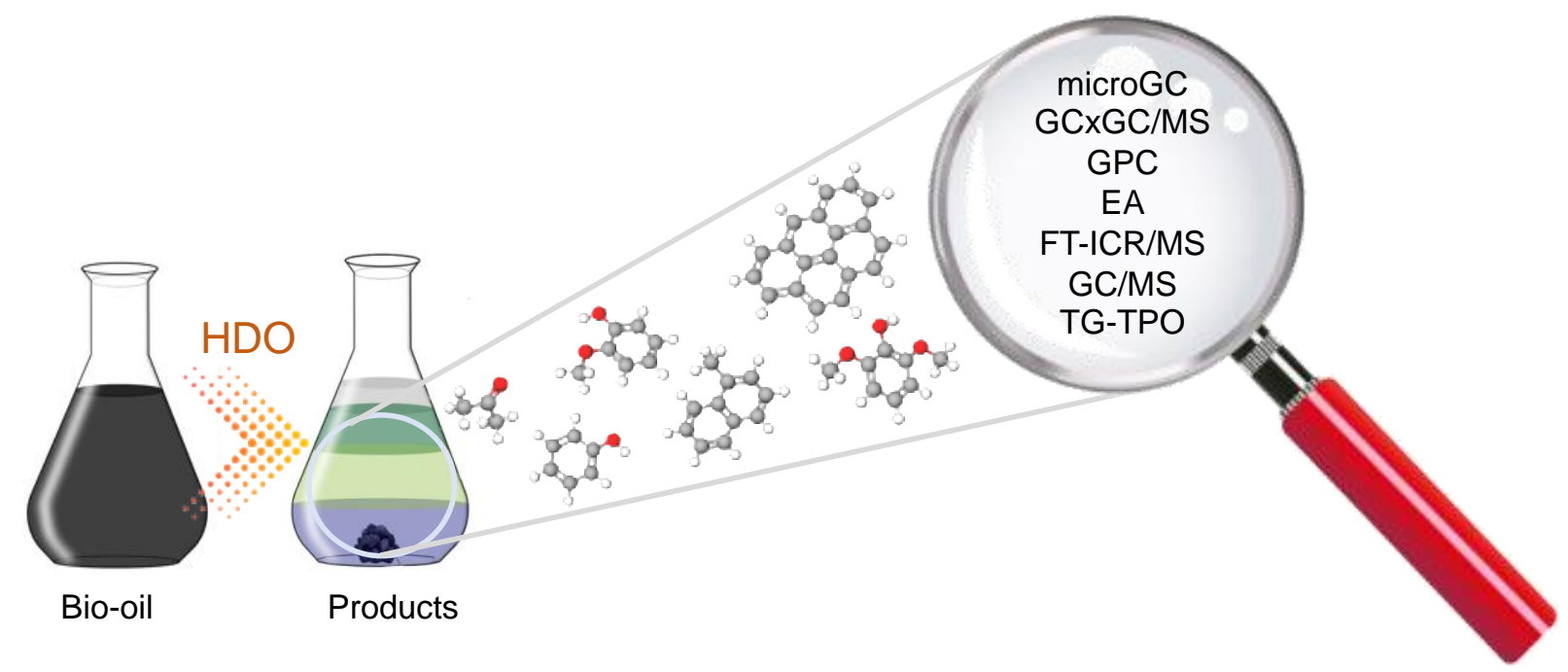

